This item was submitted to Loughborough's Research Repository by the author.

Items in Figshare are protected by copyright, with all rights reserved, unless otherwise indicated.

\title{
Current control for dual three-phase permanent magnet synchronous motors accounting for current unbalance and harmonics
}

PLEASE CITE THE PUBLISHED VERSION

http://dx.doi.org/10.1109/JESTPE.2014.2299240

PUBLISHER

(C) IEEE

VERSION

AM (Accepted Manuscript)

LICENCE

CC BY-NC-ND 4.0

\section{REPOSITORY RECORD}

Hu, Yashan, Zi-Qiang Zhu, and Kan Liu. 2019. "Current Control for Dual Three-phase Permanent Magnet Synchronous Motors Accounting for Current Unbalance and Harmonics". figshare.

https://hdl.handle.net/2134/25035. 


\title{
Current Control for Dual 3-Phase PM Synchronous Motors Accounting for Current Unbalance and Harmonics
}

\author{
Yashan Hu, Z. Q. Zhu, Fellow, IEEE, Kan Liu
}

\begin{abstract}
This paper proposes an improved vector space decomposition current control scheme for dual 3-phase magnet (PM) synchronous motors having two sets of 3-phase windings spatially shifted by 30 electrical degrees. A PI and resonant (2nd) controller is developed for eliminating the current unbalance in $\alpha \beta$ sub-plane, which is effective irrespective of the degree of current unbalance, whilst PI plus multi-frequency resonant (2nd and 6th) control is employed to eliminate the current unbalance, 5th and 7 th current harmonics in $z_{1} z_{2}$ sub-plane. Compared with existing methods only accounting for current unbalance in $z_{1} z_{2}$ sub-plane, the proposed method has taken into account the current unbalances in both $z_{1} z_{2}$ and $\alpha \beta$ sub-planes and can eliminate them simultaneously at the steady state of operation. Consequently, the full compensation of current unbalance can be achieved, by which both the current unbalance between two sets and current unbalance between phase windings in each set are eliminated. Meanwhile, the 5th and 7th current harmonics caused by non-sinusoidal back EMF and inverter non-linearity can also be fully compensated. The effectiveness of proposed method is verified by a set of comparative experiments on a prototype dual 3-phase PM machine system. It shows that fully balanced currents without the 5th and 7th current at the steady state of operation can be achieved.
\end{abstract}

Index Terms-Current harmonics, current unbalance, double star PM motor, dual three-phase, six-phase PM motor.

\section{INTRODUCTION}

$\mathrm{D}$ UAL 3-phase motor drives exhibit outstanding advantages [1-6], such as reduced phase current rating, low DC link current harmonics, less torque ripples, improved efficiency [5], excellent fault tolerant characteristics and higher reliability at system level. Consequently, dual 3-phase motor drives are widely used for electric ship propulsion, locomotive traction, electric and hybrid electric vehicles, "more-electric" aircraft [7], wind power generation [8] and high-power industrial applications, etc.

In 1993, the dual 3-phase induction machine fed by two sets of voltage source inverters was investigated in [9], as shown in Fig. 1, one set being designated as $\mathrm{ABC}$, the other set as $\mathrm{XYZ}$ shifted by $30^{\circ}$ electrical degrees. Due to the configuration of induction motor having two sets of balanced windings, with

\footnotetext{
${ }^{1}$ Manuscript received Aug 25, 2013; revised Nov 8, 2013 and Dec 19, 2013; accepted Jan 02, 2014.

The authors are with the Department of Electronic and Electrical Engineering, The University of Sheffield, Sheffield, S1 3JD, U.K. (e-mail: yashan.hu@sheffield.ac.uk; Z.Q.Zhu@sheffield.ac.uk; lkan@live.cn).

Color versions of one or more of the figures in this paper are available online at http://ieeexplore.iee.org

Digital Object Identifier 10.1109/JESTPE.2013.2287932
}

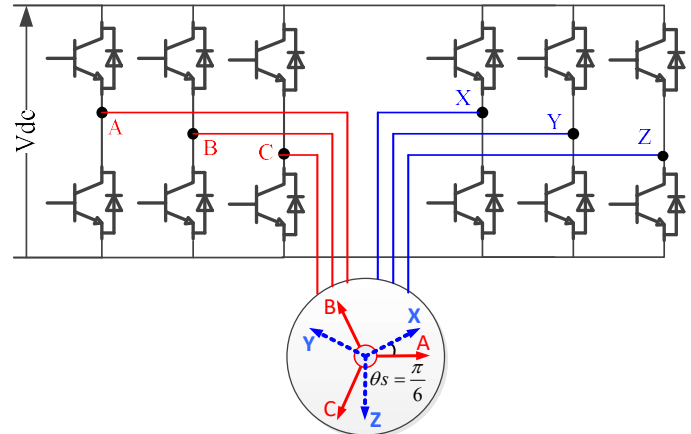

Fig. 1 Dual 3-phase system [9]

phase shift of $30^{\circ}$ electrical degrees, sixth harmonic torque pulsations produced by two sets of windings respectively are anti-phase and therefore can be completely eliminated [2].

Nowadays, numerous control strategies such as direct torque control (DTC), predictive control and vector control have been developed for dual 3-phase driver system. The DTC has the advantages of low machine parameter dependence and fast dynamic torque response and its application in drive control of dual 3-phase induction motor was discussed in [41]. In order to obtain equivalent dynamic torque response as DTC, a preferred alternative is the predictive control, which has been applied in dual 3-phase drives in recent research [42-46]. However, its applicability is hindered due to high cost in computation, whereas the vector control is popular thanks to its simplicity.

The conventional vector space decomposition (VSD) control for dual 3-phase induction motor was introduced in [10]. According to matrix transformation, the fundamental and harmonics in voltage, current, and flux vectors were projected to three sub-planes viz. $\alpha \beta, z_{1} z_{2}, o_{1} o_{2}$, which were orthogonal to each other. Therefore, the induction motor could be controlled separately in these sub-planes with full decomposition. However, the impedance in $z_{1} z_{2}$ sub-plane, related with the leakage inductance and phase winding resistance [10-12], is very small. Consequently, even if there are only small 5 th and 7 th voltage harmonics in $z_{1} z_{2}$ sub-plane, the resulting 5 th and 7 th current harmonics will be very large. Although they are not related to the electromechanical energy conversion [10], it will affect the total harmonic distortion (THD) and efficiency. In order to suppress the 5th and 7th voltage harmonics, several PWM strategies [10] [13-16] were introduced to synthesize the voltage command in $\alpha \beta$ sub-plane and maintain zero voltage in $z_{1} z_{2}$ sub-plane during each PWM period. However, there are still abundant 5 th and 7 th current harmonics due to the inverter non-linearity [17].

The conventional VSD current control scheme for dual 
3-phase motor has only two current regulators [10], The voltage references in $\alpha \beta$ sub-plane were regulated by PI controller while the voltage references in $z_{1} z_{2}$ sub-plane were assigned to zero with the assumption that the system is symmetric. In this case, the currents in $z_{1} z_{2}$ sub-plane were not controlled by closed loop. Since there are inevitable asymmetries in reality, there will be fundamental currents in $z_{1} z_{2}$ sub-plane [18]. This will cause current unbalance, i.e. the currents of phase $A B C$ and phase $\mathrm{XYZ}$ are unbalanced - not only the current amplitudes of two sets are not equal, but also the phase displacement will not be exactly $30^{\circ}$ electrical degrees [18]. In order to achieve balanced currents, current control schemes with current unbalance compensation are needed in real applications.

In fact, the conventional VSD current control is not sufficient for regulating all the current components (currents in $\alpha \beta$ and $z_{1} z_{2}$ sub-plane). In order to control the current of dual 3-phase machine effectively, 4 current regulators at a minimum are needed in reality [19], which can be mainly categorized into two types.

The first type is the double synchronous reference frames current control, which controls the two sets of windings separately, as presented in $[3,20]$ for induction motors and in [4, 21] for permanent magnet (PM) motors. The two individual current controllers in the double synchronous reference frames share the same current reference from a speed controller. Although this method can provide excellent performance for current unbalance compensation between two sets, it cannot compensate the current unbalance between phase windings in each set. Meanwhile, there are mutual coupling voltages between two sets of 3-phase windings, which are hard to compensate completely, and hence, its dynamic torque performance may be affected. In order to eliminate the effect of mutual coupling between two sets of windings, an additional matrix was introduced in [22]. The original double synchronous frames were converted to new double synchronous frames without mutual coupling between two frames. Consequently, this improved double synchronous frames model is actually equivalent to the VSD model with full decomposition. It could produce good dynamic torque performance and exhibit the capability of compensating the current unbalance [23]. However, only PI control was employed for current unbalance compensation, which was incapable to eliminate the current unbalance caused by different type of asymmetries due to limited bandwidth [17]. Meanwhile, the 5th and 7th current harmonics were only suppressed to some extent due to the limited bandwidth of PI control.

The second type is the VSD current control with unbalance compensation. The method presented in [24] was based on the conventional VSD current control [10], of which two additional PI regulators are used for current unbalance compensation. This method could provide excellent dynamic torque performance without the influence of coupling voltages between two sets. However, the current unbalance was compensated by forcing the $d-q$ axis currents of the second set to follow those of the first set, the control performance may deteriorate if the current of the first set is distorted.

The current unbalance can also be compensated by minimizing the currents in $z_{1} z_{2}$ sub-plane to be zero. In [25], currents in $z_{1} z_{2}$ sub-plane were controlled by a proportional-resonant (PR) current controller to eliminate the fundamental current in $z_{1} z_{2}$ sub-plane [18], by which the current unbalance between two sets could be consequently eliminated. However, the current unbalance between phase windings in each set as well as the 5 th, 7 th current harmonics were not taken into account.

In [17], the 5th and 7th current harmonics caused by the inverter non-linearity were compensated for a dual 3-phase induction machine drive system. Meanwhile, a generic modeling of asymmetry of a dual 3-phase phase system was presented, which included both the asymmetry between two sets and asymmetry in each set. Due to different type of asymmetries, positive and negative sequence currents could be generated in $z_{1} z_{2}$ sub-plane [26]. A combination of anti-synchronous PI and synchronous PI could be a good alternative to achieve the optimal compensation of current unbalance in $z_{1} z_{2}$ sub-plane [17]. However, the current harmonics in $\alpha \beta$ sub-plane caused by asymmetry, which corresponds to current unbalance between phase windings in each set, are not considered, meanwhile it is only focused on six-phase induction machines.

In this paper, an improved VSD current control scheme for dual 3-phase PMSMs accounting for the current unbalance and the 5th, 7 th current harmonics is proposed. Compared with the method presented in [17], the proposed method has taken into account the compensation of current unbalance in both $z_{1} z_{2}$ sub-plane and $\alpha \beta$ sub-plane, which correspond to the current unbalance between two sets and between phase windings in each set, respectively. In addition, the influence of the non-sinusoidal back electromotive force (EMF) of permanent magnet synchronous machine (PMSM) and inverter non-linearity, which generates the 5 th and 7 th current harmonics, is also investigated in details. The current unbalance in $z_{1} z_{2}$ sub-plane and the 5th and 7th current harmonics is simply compensated by extending the method presented in [17] to dual 3 -phase PMSM while the current unbalance in $\alpha \beta$ sub-plane is compensated by a proposed 2 nd order harmonic compensator. The effectiveness of proposed method is finally verified by a set of comparative experiments on a prototype dual three-phase PMSM, which shows that the proposed current control has excellent performance at the steady state of operation although the dynamic torque performance will be slightly influenced.

\section{II.MATHEMATICAL Model of DUAL THREe-Phase PMSM}

Generally, there are two types of mathematical model for dual 3-phase motor. The first is the 2-individual single 3-phase model [3, 4, 20,21], which treats dual 3-phase motor as two single 3-phase motors with coupling between two sets. The second is VSD model, which treats the dual 3-phase motor as one unit with different harmonics in different sub-planes [10]. The VSD model is prevailing because of its total decomposition, clear harmonics mapping, and easy to extend to multi-phase motor system.

According to VSD theory for dual 3-phase motor, through matrix transformation, the variables in real frame are mapped to three orthogonal sub-planes $\alpha \beta, z_{1} z_{2}, o_{1} o_{2}$ and different harmonics are mapped to different sub-planes [10]. The 
fundamental and $(12 k \pm 1)$ th, $k=1,2,3 \ldots$ harmonics were projected to $\alpha \beta$ sub-plane, the $(6 k \pm 1)$ th, $\mathrm{k}=1,3,5 \ldots$ harmonics, including 5 th and 7 th harmonics, were mapped to $z_{1} z_{2}$ sub-plane, and the zero sequence current harmonics ( $3 k$ th current harmonics, $k=0,1,2 \ldots)$ were mapped to $o_{1} o_{2}$ sub-plane. The transformation can be described as (1)

$$
\begin{aligned}
{\left[\begin{array}{lllllll}
F_{\alpha} & F_{\beta} & F_{z 1} & F_{z 2} & F_{o 1} & F_{o 2}
\end{array}\right]^{T} } \\
\quad=\left[T_{6}\right] \cdot\left[\begin{array}{lllllll}
F_{a} & F_{x} & F_{b} & F_{y} & F_{c} & F_{z}
\end{array}\right]^{T}
\end{aligned}
$$

where $F$ stands for voltage, current, or flux; a, b, and c stand for each phase of the first set of 3-phase windings; $x, y$, and $z$ stand for the second set of 3-phase windings. The matrix $\left[T_{6}\right]$ can be expressed as (2)

$$
\left[T_{6}\right]=\frac{1}{3}\left[\begin{array}{cccccc}
1 & \cos \left(\theta_{s}\right) & \cos \left(4 \theta_{s}\right) & \cos \left(5 \theta_{s}\right) & \cos \left(8 \theta_{s}\right) & \cos \left(9 \theta_{s}\right) \\
0 & \sin \left(\theta_{s}\right) & \sin \left(4 \theta_{s}\right) & \sin \left(5 \theta_{s}\right) & \sin \left(8 \theta_{s}\right) & \sin \left(9 \theta_{s}\right) \\
1 & \cos \left(5 \theta_{s}\right) & \cos \left(8 \theta_{s}\right) & \cos \left(\theta_{s}\right) & \cos \left(4 \theta_{s}\right) & \cos \left(9 \theta_{s}\right) \\
0 & \sin \left(5 \theta_{s}\right) & \sin \left(8 \theta_{s}\right) & \sin \left(\theta_{s}\right) & \sin \left(4 \theta_{s}\right) & \sin \left(9 \theta_{s}\right) \\
1 & 0 & 1 & 0 & 1 & 0 \\
0 & 1 & 0 & 1 & 0 & 1
\end{array}\right]
$$

where $\theta_{s}=\pi / 6$. In the three sub-planes, the $\alpha \beta$ sub-plane is related with electromechanical energy conversion, the currents in $z_{1} z_{2}$ sub-plane make no contribution for torque generation if the flux is sinusoidal, and there are no currents in $o_{1} O_{2}$ sub-plane for 3-phase system [10].

After the variables in $\alpha \beta$ sub-plane are obtained, by applying Park transformation (3), the synchronous mathematical model in $d q$ frame can be obtained.

$$
\left[T_{d q}\right]=\left[\begin{array}{cc}
\cos \theta & \sin \theta \\
-\sin \theta & \cos \theta
\end{array}\right]
$$

Assuming that the induced back EMF is sinusoidal, eddy current and hysteresis losses, mutual leakage inductance, and saturation are neglected, two sets of windings are symmetric, the voltage equation in $d q$ frame, $z_{1} z_{2}$ sub-plane and $o_{1} o_{2}$ sub-plane of the ideal dual 3-phase PMSM can be expressed as (4)-(6) respectively [27].

$$
\begin{aligned}
& {\left[\begin{array}{l}
v_{d} \\
v_{q}
\end{array}\right]=\left[\begin{array}{l}
\left(R_{s}+\left(L_{s l}+3 L_{d}\right) \cdot p\right) i_{d} \\
\left(R_{s}+\left(L_{s l}+3 L_{q}\right) \cdot p\right) i_{q}
\end{array}\right]+\left[\begin{array}{l}
v_{f f d_{-} d} \\
v_{f f d_{-}}
\end{array}\right]} \\
& {\left[\begin{array}{l}
v_{z 1} \\
v_{z 1}
\end{array}\right]==\left[\begin{array}{cc}
R_{s}+L_{s l} \cdot p & 0 \\
0 & R_{s}+L_{s l} \cdot p
\end{array}\right]\left[\begin{array}{l}
i_{z 1} \\
i_{z 2}
\end{array}\right]} \\
& {\left[\begin{array}{l}
v_{o 1} \\
v_{o 1}
\end{array}\right]==\left[\begin{array}{cc}
R_{s}+L_{s l} \cdot p & 0 \\
0 & R_{s}+L_{s l} \cdot p
\end{array}\right]\left[\begin{array}{l}
i_{o 1} \\
i_{o 2}
\end{array}\right]}
\end{aligned}
$$

Where

$$
\left[\begin{array}{c}
v_{f f d_{-} d} \\
v_{f f d_{-} q}
\end{array}\right]=\omega\left[\begin{array}{c}
-\left(L_{s l}+3 L_{q}\right) i_{q} \\
\left(L_{s l}+3 L_{d}\right) i_{d}
\end{array}\right]+\omega\left[\begin{array}{c}
0 \\
\psi_{f d}
\end{array}\right]
$$

where $p$ is differential operator, $R_{s}$ is the stator winding resistance. $L_{s l}$ is the stator leakage inductance. $L_{d}$ and $L_{q}$ are the $d q$-axis self-inductances of each phase respectively. $\psi_{f d}$ is permanent magnet flux. $\omega$ is the electrical angular speed. $i_{d}, v_{d}$, $i_{q}$, and $v_{q}$ are the $d q$-axis currents and voltages for dual 3-phase machine respectively. $v_{f f d_{d} d}$ and $v_{f f d_{q} q}$ are decoupling voltages in $d q$ frame. $i_{z 1}, i_{z 2}, v_{z 1}$ and $v_{z 2}$ are currents and voltages in $z_{1} z_{2}$ sub-plane respectively. $i_{o 1}, i_{o 2}, v_{o 1}$ and $v_{o 2}$ are currents and voltages in $o_{1} O_{2}$ sub-plane respectively.

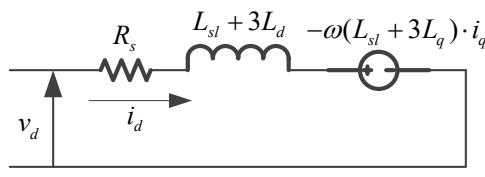

(a)

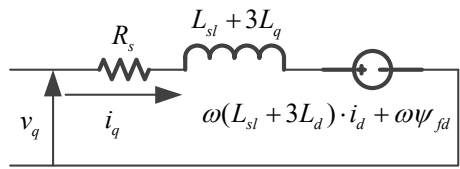

(b)

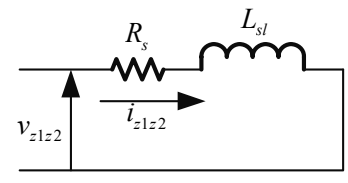

(c)

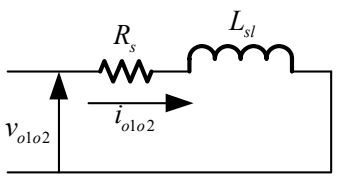

(d)
Fig. 2 Equivalent circuit for dual 3-phase PMSM (a) $d$-axis equivalent circuit in $\alpha \beta$ sub-plane, (b) $q$-axis equivalent circuit in $\alpha \beta$ sub-plane, (c) Equivalent circuit in $z_{1} z_{2}$ sub-plane, (d) Equivalent circuit in $o_{1} o_{2}$ sub-plane

The equivalent circuit for (4)-(6) can be expressed as Fig. 2. From Fig. 2, it can be seen that the control for dual 3-phase PMSM is decomposed completely. The vector control for dual 3-phase PMSM could be as simple as vector control for single 3-phase PMSM.

\section{Proposed Current Control Scheme}

In this section, the principle of current unbalance compensation will be firstly introduced, and then two major sources causing 5 th and 7 th current harmonics will be analyzed in details. Followed by the principle of 5th and 7th current harmonics compensation, an improved VSD current scheme accounting for current unbalance and 5th and 7th current harmonics will be proposed.

\section{A.Current Unbalance Compensation}

The asymmetry in dual 3-phase driver system is inevitable due to the asymmetry between two sets of windings, asymmetry between windings in each set and asymmetry in power inverter. According to [17], the unbalanced currents can be expressed as a combination of positive and negative sequence currents, which are caused by different type of asymmetry [26]. When $i_{d}=0$ control strategy is employed, the unbalanced currents of each set can be expressed as (assuming no phase angle lead/lag between positive and negative sequence current for simplicity).

$$
\begin{aligned}
& i_{\alpha \beta 1}=k_{1} I_{m} \cdot e^{j\left(\theta+\frac{\pi}{2}\right)}+k_{2} I_{m} \cdot e^{-j\left(\theta+\frac{\pi}{2}\right)} \\
& i_{\alpha \beta 2}=k_{3} I_{m} \cdot e^{j\left(\theta+\frac{\pi}{2}\right)}+k_{4} I_{m} \cdot e^{-j\left(\theta+\frac{\pi}{2}\right)}
\end{aligned}
$$

where coefficients $k_{i}, i=1,2,3,4$, depend on the type of the asymmetry [17]. $i_{\alpha \beta 1}$ and $i_{\alpha \beta 2}$ are the currents of phase $\mathrm{ABC}$ and phase XYZ in $\alpha \beta$ frame respectively, $\theta$ is the rotor position.

The variables in $z_{1} z_{2}$ sub-plane can be converted to a new frame, designated as $d q z$ frame, by using the matrix conversion of $\left[T_{d q z}\right]$. 


$$
\begin{gathered}
{\left[T_{d q z}\right]=\left[\begin{array}{cc}
-\cos \theta & \sin \theta \\
\sin \theta & \cos \theta
\end{array}\right]} \\
{\left[\begin{array}{l}
F_{d z} \\
F_{q z}
\end{array}\right]=\left[\begin{array}{l}
T_{d q z}
\end{array}\right]\left[\begin{array}{l}
F_{z 1} \\
F_{z 2}
\end{array}\right]}
\end{gathered}
$$

where $F$ is $v, i$, or $\psi$, which is corresponding with voltage, current, and stator flux, respectively.

From (8)(9) and inverse Clark transformation, the current of each phase can be obtained, then $i_{z 1}$ and $i_{z 2}$ can be calculated by (1) and expressed as (12). It can be seen there are fundamental currents in $z_{1} z_{2}$ sub-plane, which is in accordance with [18].

$$
\left[\begin{array}{c}
i_{z 1} \\
i_{z 2}
\end{array}\right]=-\frac{I_{m}}{2}(\underbrace{\left[\begin{array}{c}
\left(k_{1}-k_{3}\right) \sin (\theta) \\
\left(k_{1}-k_{3}\right) \cos (\theta)
\end{array}\right]}_{\text {Negative sequence }}+\underbrace{\left.\left[\begin{array}{c}
\left(k_{2}-k_{4}\right) \sin (\theta) \\
-\left(k_{2}-k_{4}\right) \cos (\theta)
\end{array}\right]\right)}_{\text {Positive sequence }}
$$

After the transformation(11), $i_{d z}$ and $i_{q z}$ in $d q z$ frame can be expressed as

$$
\left[\begin{array}{l}
i_{d z} \\
i_{q z}
\end{array}\right]=\frac{I_{m}}{2}(\underbrace{\left[\begin{array}{c}
0 \\
-\left(k_{1}-k_{3}\right)
\end{array}\right]}_{\text {DC }}+\underbrace{\left(k_{2}-k_{4}\right)\left[\begin{array}{c}
\sin (2 \theta) \\
\cos (2 \theta)
\end{array}\right]}_{\text {Second order }})
$$

It can be seen that negative and positive sequence currents in (12) are converted to DC currents and 2nd order harmonics in (13) in $d q z$ frame respectively. By eliminating the DC values and 2 nd order current harmonics in $d q z$ frame, the current unbalance in $z_{1} z_{2}$ sub-plane can be eliminated. It is equivalent as the method presented in [17], where combination of synchronous frame PI and anti-synchronous frame PI were used to obtain full compensation of current unbalance in $z_{1} z_{2}$ sub-plane.

If the current unbalance in $z_{1} z_{2}$ sub-plane is eliminated, $i_{d z}$ and $i_{q z}$ will be zero. In this case, the following equation can be obtained from (13)

$$
k_{1}=k_{3}, \quad k_{2}=k_{4}
$$

Equation (14) means the unbalance between two sets of 3-phase windings is eliminated; two sets have same positive and same negative sequence currents. However, it does not mean $k_{2}$ and $k_{4}$ are zero. If $k_{2}$ and $k_{4}$ are non-zero, negative sequence currents will still exist in(8) and (9), which indicates the phase currents in each set are still unbalanced.

In [17], the current unbalance in $z_{1} z_{2}$ sub-plane was considered, however, the current unbalance in $\alpha \beta$ sub-plane was not considered. When the currents are unbalanced, there will have positive and negative sequence currents in $\alpha \beta$ sub-plane as well. From (8)(9) and inverse Clark conversion, the current of each phase can be obtained, then $i_{\alpha}$ and $i_{\beta}$ can be calculated by (1) and expressed as

$$
\left[\begin{array}{l}
i_{\alpha} \\
i_{\beta}
\end{array}\right]=\frac{I_{m}}{2}(\underbrace{\left(\begin{array}{c}
-\left(k_{1}+k_{3}\right) \cdot \sin (\theta) \\
\left(k_{1}+k_{3}\right) \cdot \cos (\theta)
\end{array}\right)}_{\text {Positive sequence }}+\underbrace{\left(\begin{array}{c}
-\left(k_{2}+k_{4}\right) \cdot \sin (\theta) \\
-\left(k_{2}+k_{4}\right) \cdot \cos (\theta)
\end{array}\right)}_{\text {Negative sequence }})
$$

By applying (3) to (15), the $d q$-axis currents can be expressed as (16)

$$
\left[\begin{array}{l}
i_{d} \\
i_{q}
\end{array}\right]=\frac{I_{m}}{2}(\underbrace{\left[\begin{array}{c}
0 \\
k_{1}+k_{3}
\end{array}\right]}_{\mathrm{DC}}-\underbrace{\left(k_{2}+k_{4}\right)\left[\begin{array}{c}
\sin (2 \theta) \\
\cos (2 \theta)
\end{array}\right]}_{\text {Second order }})
$$

From (16), it can be seen that when there are negative sequence currents in each set caused by asymmetry, 2nd order current harmonics may exist in $d q$-axis currents $\left(k_{2}+k_{4} \neq 0\right)$. If the 2nd order harmonics in $d q$ frame are eliminated as well, which means

$$
k_{2}+k_{4}=0
$$

Combining (14) and (17) together, the following equations can be obtained

$$
k_{1}=k_{3}, \quad k_{2}=k_{4}=0
$$

In this case, $i_{\alpha \beta 1}$ in (8) will be equal to $i_{\alpha \beta 2}$ in (9), meanwhile, there are only positive sequence currents exist, which means the currents are totally balanced, viz. balance between two sets and between windings in each set.

The current unbalance in $\alpha \beta$ sub-plane has significant influence on torque ripple. For example, the 2 nd order torque ripple will be generated due to the interaction between the negative sequence currents and positive sequence fluxes in $\alpha \beta$ sub-plane. If the current unbalance can be completely compensated, there are only positive sequence currents in $\alpha \beta$ sub-plane. If the fluxes are unbalanced, there will have positive and negative sequence fluxes in $\alpha \beta$ sub-plane, which have similar expression as (15). The positive sequence currents in $\alpha \beta$ sub-plane will interact with positive and negative sequence fluxes in $\alpha \beta$ sub-plane and generate average torque and 2nd order torque ripple. However, if the fluxes are balanced and the asymmetry is caused by resistor or inverter asymmetry, there are only positive sequence fluxes in $\alpha \beta$ sub-plane. In this case, 2nd order torque ripple will not be generated.

\section{B. Fifth and Seventh Current Harmonics Compensation}

In [17], a 6th order resonant controller was employed to compensate 5 th and 7 th current harmonics caused by dead-time effect for asymmetric 6-phase machine. However, for the dual 3-phase PMSM, the 5th and 7th current harmonics are not only resulted from the inverter non-linearity, but also from non-sinusoidal back EMF.

\section{1) Due to Non-Sinusoidal Back EMF}

There are 5th and 7th harmonics in the back EMF inevitably in reality [4].. The back EMFs of phase A and phase X of the prototype machine are shown in Fig. 3 (a); line back EMFs of phase ABC are shown in Fig. 3(b). From Fig. 3(b), it can be seen that the line back EMF profiles are not pure sinusoidal, with abundant harmonics, being dominated by the 5th and 7 th harmonics, as shown in Fig. 3 (c). After matrix transformation (2) and (11), the 5th, 7th flux harmonics are mapped to 6th flux harmonics $\psi_{f d z}$ and $\psi_{f q z}$ in $d q z$ frame, Fig. 3 (d).

\section{2) Due to Inverter Non-linearity}

According to $[28,29]$, the distorted phase voltage caused by inverter non-linearity is related with the phase current direction, which can be simplified as

$$
V_{\text {phs_dead }}=\operatorname{sign}\left(i_{\text {phs }}\right) * V_{\text {dead }}
$$




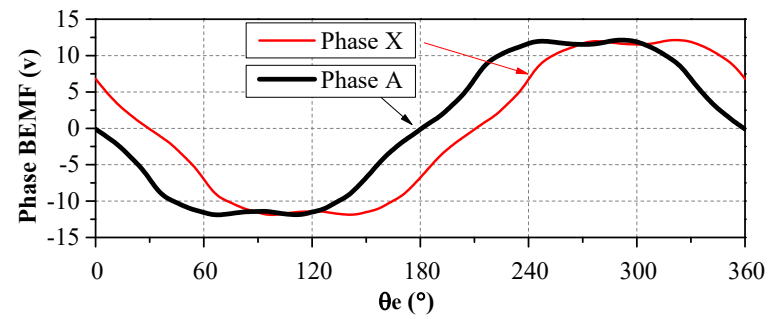

(a)

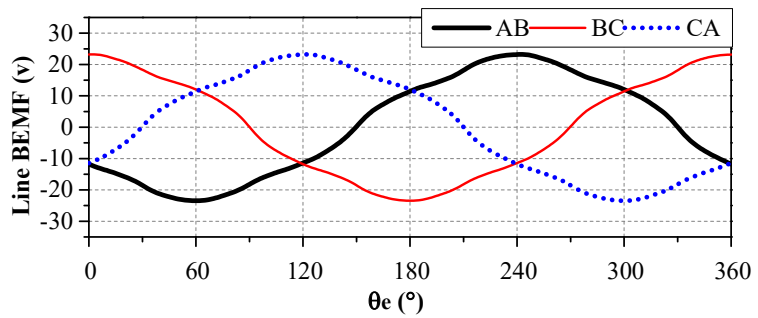

(b)

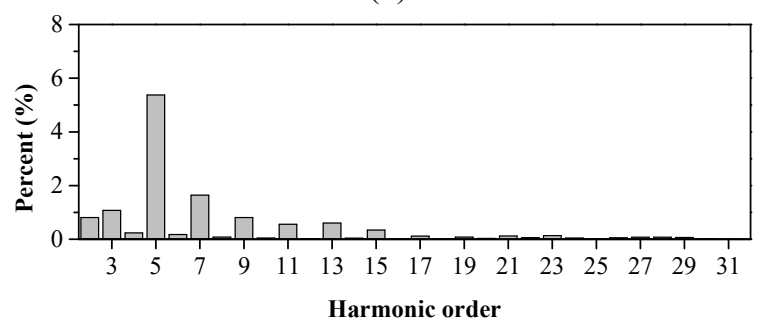

(c)

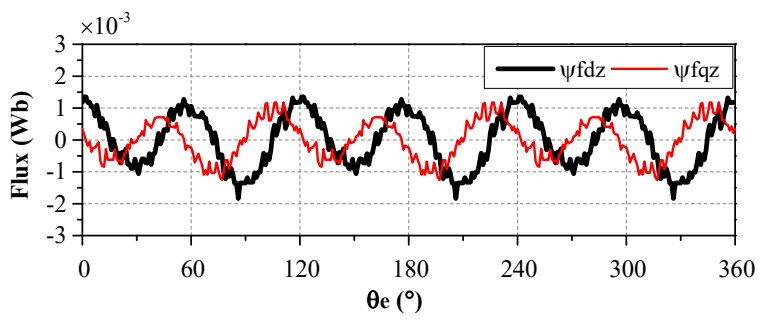

(d)

Fig. 3 Measured back EMFs (a) Phase back EMF, (b) Line back EMF between Phases A and B, (c) Harmonic analysis of line back EMF between Phases A and $\mathrm{B}$, (d) Flux in $d q z$ frame obtained from measured back EMFs

where $p h s$ stands for phase A, B, C, X, Y, or Z, $V_{\text {dead }}$ stands for the magnitude of distorted voltage caused by inverter non-linearity.

Assuming $V_{\text {dead }}$ is equal to $2 \mathrm{~V}$, from the harmonics analysis of $V_{A \text { dead }}$ shown in Fig. 4(a), it can be seen that abundant odd voltage harmonics exist in $V_{A \text { dead }}$. Since the fundamental distorted voltages can be effectively compensated by PI controller and 3rd voltage harmonics have no influence in the 3-phase system, the 5th and 7 th voltage harmonics will have dominant effect on current harmonics.

The distorted voltages for each single 3-phase system in $d q$ frame are shown in Fig. 4(b) when the $i_{d}=0$ control strategy is employed. $D V_{d 1}, D V_{q 1}, D V_{d 2}$ and $D V_{q 2}$ are the distorted $d q$-axis voltages for phase $\mathrm{ABC}$ and $\mathrm{XYZ}$ respectively. The abundant 6th voltage harmonics caused by inverter non-linearity will cause 6th current harmonics in $d q$-axis currents of each single 3-phase.
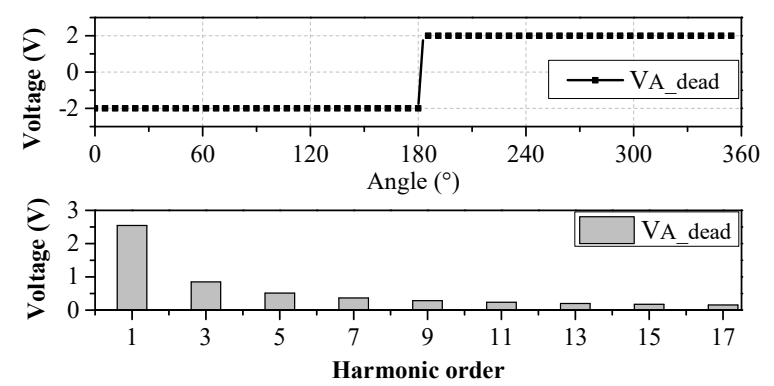

(a)
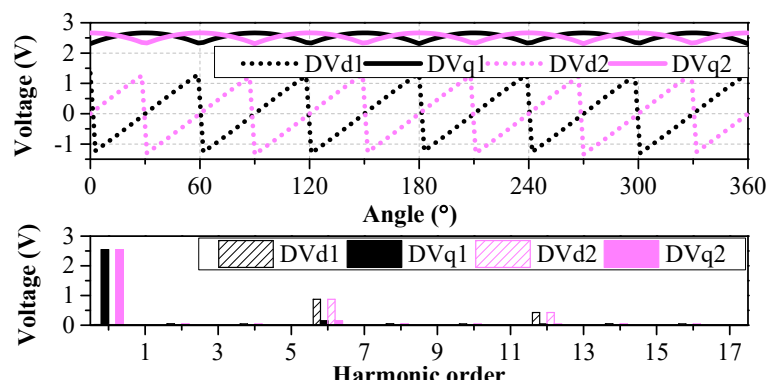

(b)
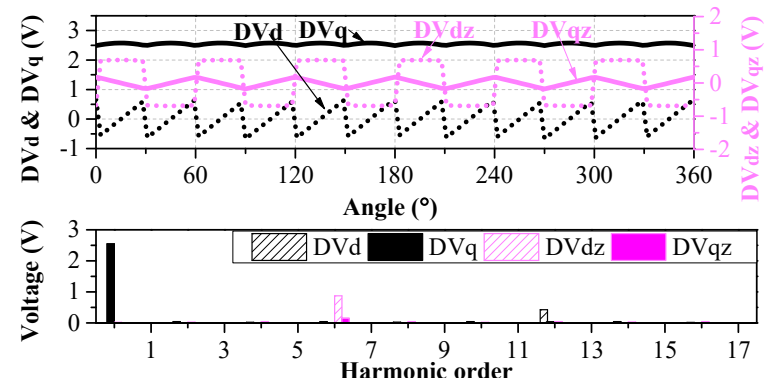

(c)

Fig. 4 Distorted voltage caused by non-linearity of inverter (a) Harmonic analysis for distorted voltage for phase A, (b) Distorted voltages in $d q$-axis for each set of single 3-phase, (c) Distorted voltage in $d q$ frame and $d q z$ frame for dual 3-phase

The distorted voltages in $d q$ frame and $d q z$ frame for dual 3-phase system are shown in Fig. 4(c). $D V_{d}$ and $D V_{q}$ are the distorted $d q$-axis voltages for dual 3-phase system. It worth noting that there are no 6th voltage harmonics in $D V_{d}$ and $D V_{q}$, while the 12 th voltage harmonics are significant, which means it will cause 12th current harmonics in $d q$-axis currents for a dual 3-phase system. $D V_{d z}$ and $D V_{q z}$ are the distorted voltages in $d q z$ frame; the 6th voltage harmonics are dominant in $d q z$ frame, Fig. 4(c), which will generate corresponding current harmonics in $d q z$ frame.

\section{3) Principle of Fifth and Seventh Current Harmonics Compensation}

Considering the non-sinusoidal back EMF and inverter non-linearity, 5th, 7th current harmonics in phase currents are inevitable, in order to reduce the current total harmonic distortion and increase efficiency, they should be eliminated.

Assuming the 5th and 7 th harmonics in the phase current, voltage or flux can be expressed as (20) 


$$
\left[\begin{array}{l}
F_{a} \\
F_{x} \\
F_{b} \\
F_{y} \\
F_{c} \\
F_{z}
\end{array}\right]=F_{5}\left[\begin{array}{c}
\cos \left((5 \theta)+\theta_{5}\right) \\
\cos \left(5\left(\theta-\theta_{s}\right)+\theta_{5}\right) \\
\cos \left(5\left(\theta-4 \theta_{s}\right)+\theta_{5}\right) \\
\cos \left(5\left(\theta-5 \theta_{s}\right)+\theta_{5}\right) \\
\cos \left(5\left(\theta-8 \theta_{s}\right)+\theta_{5}\right) \\
\cos \left(5\left(\theta-9 \theta_{s}\right)+\theta_{5}\right)
\end{array}\right]+F_{7}\left[\begin{array}{c}
\cos \left((7 \theta)+\theta_{7}\right) \\
\cos \left(7\left(\theta-\theta_{s}\right)+\theta_{7}\right) \\
\cos \left(7\left(\theta-4 \theta_{s}\right)+\theta_{7}\right) \\
\cos \left(7\left(\theta-5 \theta_{s}\right)+\theta_{7}\right) \\
\cos \left(7\left(\theta-8 \theta_{s}\right)+\theta_{7}\right) \\
\cos \left(7\left(\theta-9 \theta_{s}\right)+\theta_{7}\right)
\end{array}\right]
$$

where $\theta_{5}$ and $\theta_{7}$ are the offset electrical angles of 5 th and 7 th harmonics respectively. $F_{5}$ and $F_{7}$ are the amplitudes of 5 th and 7 th harmonics respectively.

By converting the variables of each set shown in (20) to $d q$ frame respectively, the following relationship can be obtained.

$$
\left\{\begin{array}{l}
F_{d 1_{-} 6 t h}=-F_{d 2_{-} 6 t h}=F_{5} \cdot \cos \left(6 \theta+\theta_{5}\right)+F_{7} \cdot \cos \left(6 \theta+\theta_{7}\right) \\
F_{q 1_{-} 6 t h}=-F_{q 2_{-} 6 t h}=-F_{5} \cdot \sin \left(6 \theta+\theta_{5}\right)+F_{7} \cdot \sin \left(6 \theta+\theta_{7}\right)
\end{array}\right.
$$

where $F_{d 1 \_6 t h}$ and $F_{q 1 \_} 6 t h$ are $d q$-axis 6 th harmonics for phase ABC, $F_{d 2}{ }_{\text {tth }}$ and $F_{q 2}$ th are $d q$-axis 6 th harmonics for phase $X Y Z$. The equation (21) means the 5 th and 7 th harmonics in real frame are converted to 6th harmonics in $d q$-axis for single 3 -phase $\mathrm{ABC}$ and $\mathrm{XYZ}$ respectively, they have same amplitude, but anti-phase.

By applying matrix (2) to (20), the 5 th and 7 th harmonics will be projected to $z_{1} z_{2}$ sub-plane, and then by applying (10) to variables in $z_{1} z_{2}$ sub-plane, the 5th and 7th harmonics will be converted to 6th harmonics in $d q z$ frame. It can be concluded that the 6th current harmonics in $d q z$ frame have the following relationship.

$$
\left[\begin{array}{l}
i_{d z_{-} 6 t h} \\
i_{q z_{-} 6 t h}
\end{array}\right]=-\left[\begin{array}{l}
i_{d 1_{-} 6 t h} \\
i_{q 1_{-} 6 t h}
\end{array}\right]=\left[\begin{array}{l}
i_{d 2_{-} 6 t h} \\
i_{q 2_{-} 6 t h}
\end{array}\right]
$$

From (22), it can be seen that by suppressing the 6th current harmonics in $d q z$ frame, the 6th current harmonics in $d q$ frame for each set can be suppressed simultaneously. Consequently, the 5th and 7th current harmonics in each phase can be suppressed simultaneously.

\section{Proposed Current Control Scheme}

The PI controller is incapable of eliminating AC errors because of its limited bandwidth. To eliminate AC errors in steady state operation, the PR control, which could track sinusoidal signal reference with zero error if the reference signal had a fixed frequency, was introduced in [30-32]. The modified PI control with resonant control (PI-R) was used widely in 3 -phase grid current control when the grid voltage was unbalanced or not sinusoidal [33-40]. In this paper, the resonant control will be employed to eliminate current unbalance and 5 th and 7 th current harmonics.

The proposed current control scheme is shown in Fig. 5. The $i_{d z}^{*}$ and $i_{q z}^{*}$ are assigned to zero aiming for current unbalance and 5 th and 7 th current harmonics compensation in $z_{1} z_{2}$ sub-plane. Since there are no currents flowing in $o_{1} o_{2}$ sub-plane, the voltages in $o_{1} o_{2}$ sub-plane are assigned to zero. Compared with the conventional VSD current scheme [10], current control in $d q z$ frame is included, PI control is used to regulate the DC error, while the multi-frequency resonant controls are used to eliminate 2nd order and 6th current harmonics in $d q z$ frame.

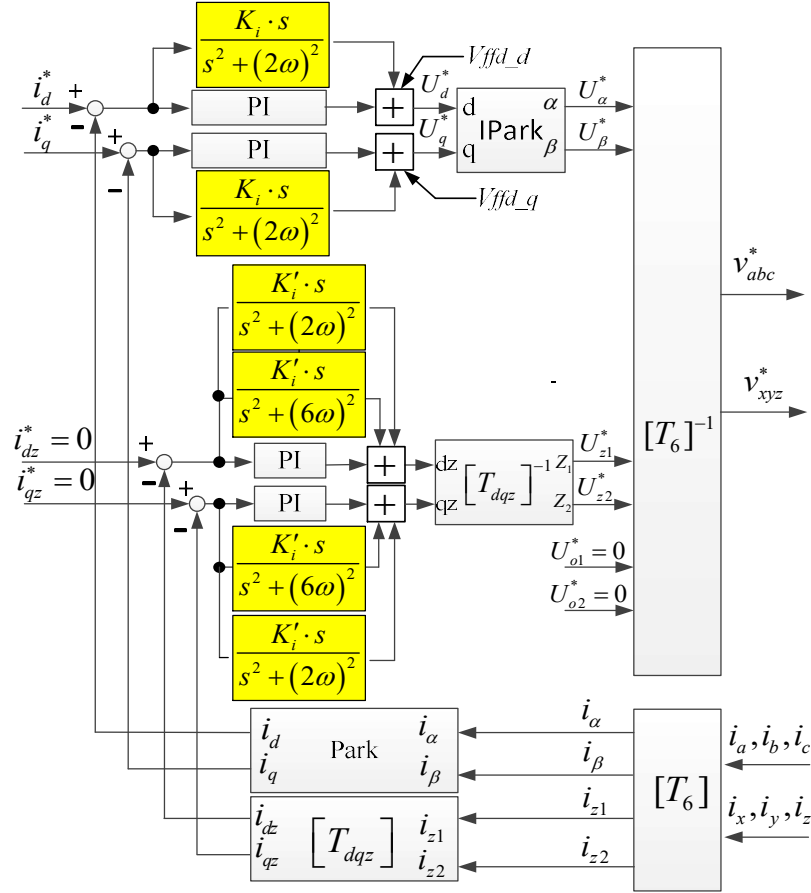

Fig. 5 Current control flowchart of proposed method

Unlike the method presented in [17], which only considered the current unbalance in $z_{1} z_{2}$ sub-plane for dual 3-phase induction motor system, the proposed method considers the current unbalance in $z_{1} z_{2}$ and $\alpha \beta$ sub-plane for dual 3-phase PMSM simultaneously. The proposed resonant control is employed to eliminate the 2nd order current harmonics in $d q$ frame caused by current unbalance.

It is worth noting that the practical resonant control is usually implemented by replacing the ideal integrator with an approximated low-pass filter transfer function [31]. The gains and cut frequency of low-pass filter are very important considering the stability [31]. However, it is beyond the scope of this paper. For simplicity, the cut-frequency is chosen as $1 / 200$ times of resonant frequency, and the integral gain of resonant control is set to be the same as the integral gain of PI control [17].

By matrix (23) conversion, the output of current controllers for $i_{d z}, i_{q z}$ are converted to $U_{z 1}^{*}, U_{z 2}^{*}$.

$$
\left[T_{d q z}\right]^{-1}=\left[T_{d q z}\right]^{T}=\left[\begin{array}{cc}
-\cos \theta & \sin \theta \\
\sin \theta & \cos \theta
\end{array}\right]
$$

After all the voltages of six-dimensions $U_{\alpha}^{*}, U_{\beta}^{*}, U_{z 1}^{*}, U_{z 2}^{*}$, $U_{o 1}^{*}, U_{o 2}^{*}$ are obtained, the phase voltage references can be obtained by inverse $\left[\mathrm{T}_{6}\right]$ transformation (24), then The conventional SVPWM strategy is applied for PWM generation.

$$
\left[T_{6}\right]^{-1}=3\left[T_{6}\right]^{T}
$$

\section{EXPERIMENTS}

The hardware platform to evaluate the effectiveness of the proposed method is constructed based on dSPACE DS1005. The experimental setup is shown in Fig. 6. The prototype dual 3 -phase PMSM is coupled with a permanent magnet DC motor, which is connected with an adjustable power resistor used as 
load. The Dual 3-phase driver is constructed by two single 3-phase drives, which have same power inverter topology as Fig. 1. The calculation rate of the current loop is configured to be 10 $\mathrm{kHz}$, which is the same as the PWM frequency. The currents are sampled by DS2002 A/D board in dSPACE system, which has 16-bit resolution. The corresponding current sample resolution is $0.38 \mathrm{~mA}$. The $2 \mu \mathrm{s}$ dead-time is used to avoid short-circuit of power switching bridge. Two independent SVPWM modulators for each single 3-phase are used for PWM generation. The design parameters of prototype dual 3-phase PMSM are shown in TABLE I. The design principle of PI parameters is the same as that in [47] and the overall time delay including the PWM output delay, current sampling delay and processing delay, is approximately 1.5 times of PWM period. Thus, the optimized PI parameters can be derived by setting the damping factor to 0.707 and are listed in TABLE II.

\section{A. Fifth and Seventh Current Harmonics Compensation}

In this experiment, the driver works in constant current control mode without/with 5th and 7th current harmonics compensation, the $i_{q}$ reference is $1.5 \mathrm{~A}$. The test results without compensation are shown in Fig. 7. It can be seen that the current of phase $A$ and $X$ are not pure sinusoidal, Fig. 7(a), and the 5th and 7 th current harmonics are dominant. After $i_{z 1}, i_{z 2}$ are transformed to $i_{d z}, i_{q z}$ in Fig. 7(b), obvious 6th harmonics can be found in $i_{d z}, i_{q z}$. It can also be seen that the $d q$-axis currents $i_{d l}$, $i_{d 2}$ in Fig. 7(c) and $i_{q 1}, i_{q 2}$ in Fig. 7(d) for each set have 6th current harmonics, but they are anti-phase, which is in accordance with (21). Consequently, there is no 6th current harmonic in $i_{d}$ and $i_{q}$ for dual 3-phase system.

The test results with compensation are shown in Fig. 8. The current profiles of phase $\mathrm{A}$ and $\mathrm{X}$ in Fig. 8(a) are more sinusoidal than that in Fig. 7(a) due to the 6th current harmonics of $i_{d z}, i_{q z}$ in Fig. 8(b) are eliminated. The 6th current harmonics in $d$-axis current $i_{d 1}$ and $i_{d 2}$ for each single 3-phase in Fig. 8(c) are effectively suppressed compared with those in Fig. 7(c). The 6 th current harmonics in $q$-axis current $i_{q 1}$ and $i_{q 2}$ for each single 3 -phase in Fig. 8(d) are effectively suppressed compared with those in Fig. 7(d).

It is worth noting that $i_{d}$ and $i_{q}$ in Fig. 8 are corresponding to the right y-axis of Fig. 8 (c) and (d), respectively. An interesting phenomenon is that $i_{d}$ in Fig. 7(c) and Fig. 8(c) has distinct 12th current harmonics, while $i_{q}$ in Fig. 7(d) and Fig. 8(d) does not have apparent 12th current harmonic. This is because the 12th voltage harmonics caused by inverter non-linearity in $d$-axis is larger than that in $q$-axis, as shown in Fig. 4(c). Current Unbalance Compensation in Steady State Operation

In this experiment, a $0.5 \Omega$ resistor is deliberately connected in series with phase A. The system works in constant current mode, the reference of $i_{a}$ is $1.5 \mathrm{~A}$.

The measured phase current and $i_{d z}, i_{q z}$ of conventional VSD current control without current control in $z_{1} z_{2}$ sub-plane are shown in Fig. 9(a) (b) respectively. Fig. 9 (a) shows that $i_{a}$ and $i_{x}$ are seriously unbalanced. The $i_{d z}$ and $i_{q z}$ have obvious 6 th current harmonics in Fig. 9 (b).

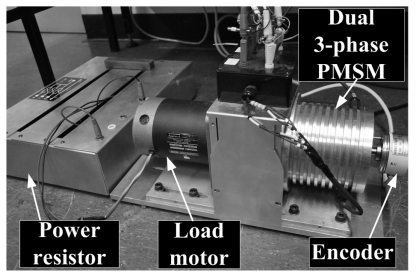

(a)

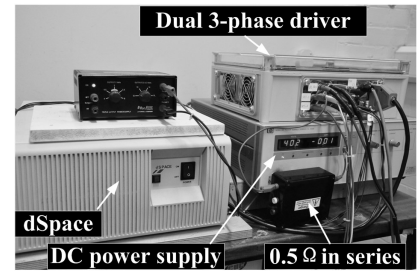

(b)
Fig. 6 Experimental setup for dual 3-phase PMSM drive (a) Test dual 3-phase PMSM, (b) Dual 3-phase drive system

TABLE I

PARAMETERS OF PRototyPe DUAL 3-PHASE PMSM

\begin{tabular}{ll}
\hline Parameters & Value \\
\hline Resistance $(\Omega)$ & 1.096 \\
Leakage inductance $(\mathrm{mH})$ & 0.875 \\
$d$-axis self-inductance $(\mathrm{mH})$ & 2.141 \\
$q$-axis self-inductance $(\mathrm{mH})$ & 2.141 \\
Flux linkage $(\mathrm{Wb})$ & 0.075 \\
Pole pairs & 5 \\
Power $(\mathrm{W})$ & 240 \\
DC link voltage $(\mathrm{V})$ & 40 \\
\hline
\end{tabular}

TABLE II

PARAMETERS OF REGULATORS

\begin{tabular}{ll}
\hline Parameters & Value \\
\hline Proportional gain of PI in $d q$ frame & 24.33 \\
Integral gain of PI in $d q$ frame & 3654.43 \\
Integral gain of resonant controller in $d q$ frame & 3654.43 \\
Proportional gain of PI in $d q z$ frame & 2.92 \\
Integral gain of PI in $d q z$ frame & 3654.43 \\
Integral gain of resonant controller in $d q z$ frame & 3654.43 \\
\hline
\end{tabular}

From the harmonic analysis of $i_{d z}$ and $i_{q z}$ shown in the lower part of Fig. 9 (b), it can be seen that the 6th current harmonics, DC value and 2 nd order current harmonics are dominant. The $i_{d}$ and $i_{q}$ current profiles and corresponding harmonic analysis are shown in Fig. 9 (c) and Fig. 9 (d) respectively. It can been seen that there are 2 nd current harmonics in $i_{d}$ and $i_{q}$, which is in accordance with(16).

The experimental results with PI-R(6th) control in $d q z$ frame are shown in Fig. 10, which shows that the phase current profiles in Fig. 10(a) have been improved significantly compared with those in Fig. 9(a). In addition, as can be seen from Fig. 10 (b), the dominant DC value and 6th current harmonic in $i_{d z}$ and $i_{q z}$ have been eliminated compared with those in Fig. 9(b).

Furthermore, it is also evident that the 2nd current harmonics in Fig. 10 (b) are suppressed greatly compared with that in Fig. 9(b). However, from Fig. 10 (b), there are still residual 2nd current harmonics in $i_{d z}$ and $i_{q z}$ while there are also residual 2 nd current harmonics in $i_{d}$ and $i_{q}$, as shown in Fig. 10 (c) and Fig. 10 (d).
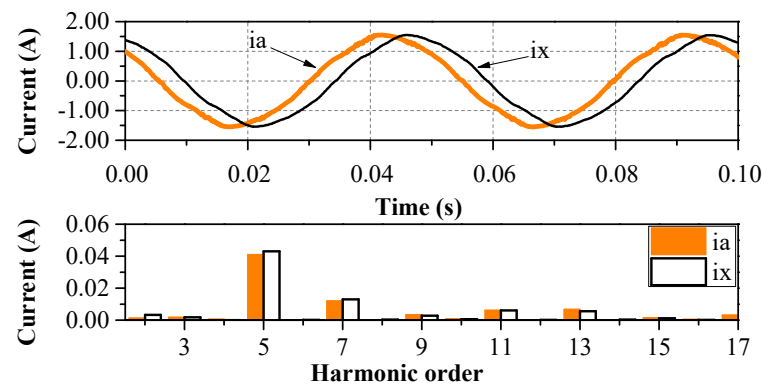

(a) 

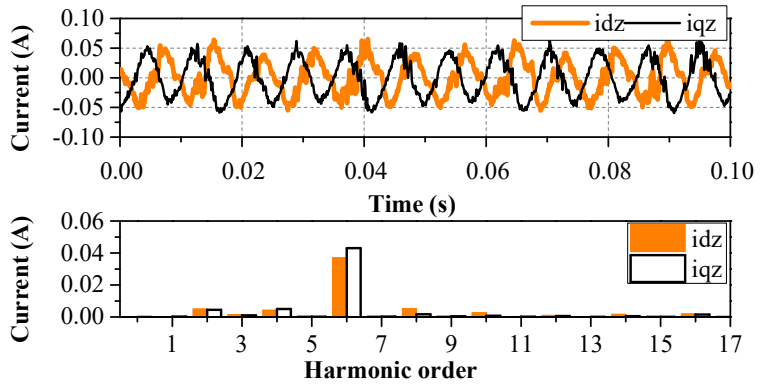

(b)
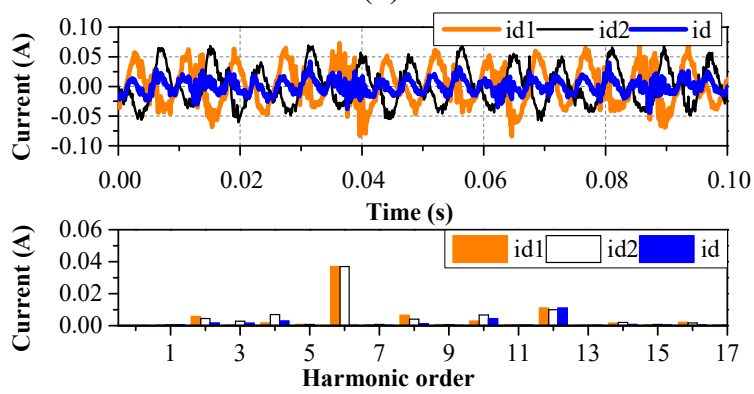

(c)
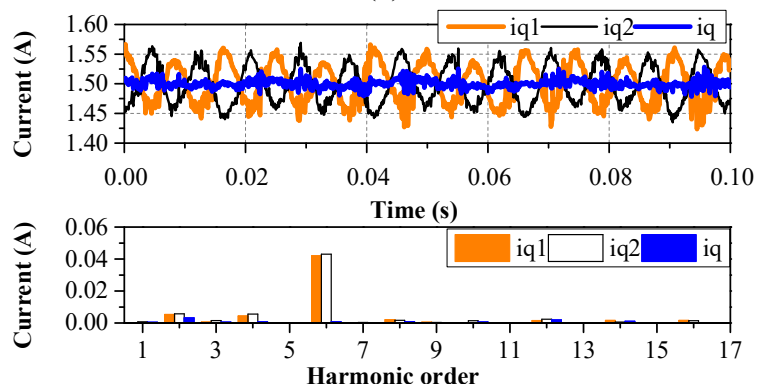

(d)

Fig. 7 Measured results without 5th and 7th harmonics compensation (a) Phase $\mathrm{A}$ and $\mathrm{X}$ current and harmonic analysis, (b) $i_{d z}$ and $i_{q z}$ and harmonic analysis, (c) $d$-axis current and harmonic analysis, (d) $q$-axis current and harmonic analysis

To eliminate the 2nd current harmonics in $d q z$ frame, the PI-R(6th) control in $d q z$ frame with an additional 2nd order resonant control in $d q z$ frame is employed, which is equivalent as the method presented in [17]. As can be seen from the experimental results shown in Fig. 11, it is evident that although the phase current profiles shown in Fig. 11(a) change insignificantly compared with those in Fig. 10(a), the 2nd current harmonics in $i_{d z}$ and $i_{q z}$ shown in Fig. 11(b) have been eliminated effectively compared with those in Fig. 10(b). However, there are still slight 2 nd current harmonics in $i_{d}$ and $i_{q}$, as can be seen from Fig. 11(c) and Fig. 11(d).

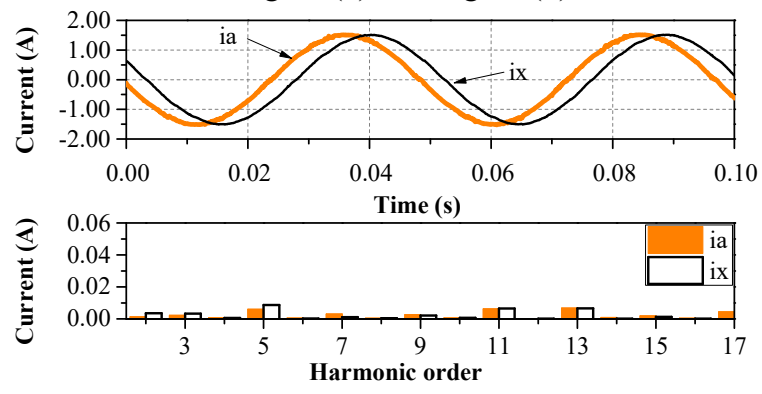

(a)
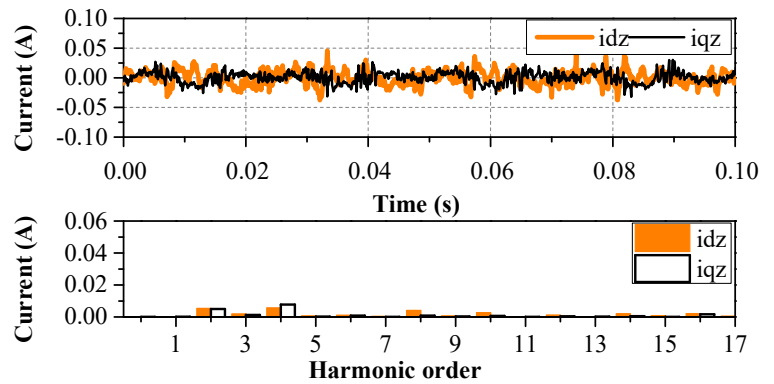

(b)
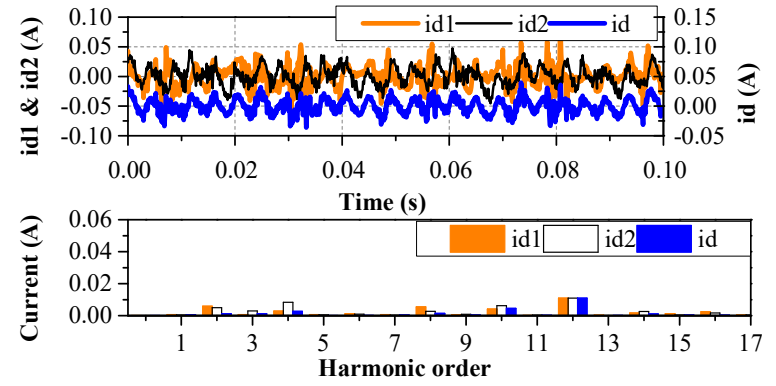

(c)

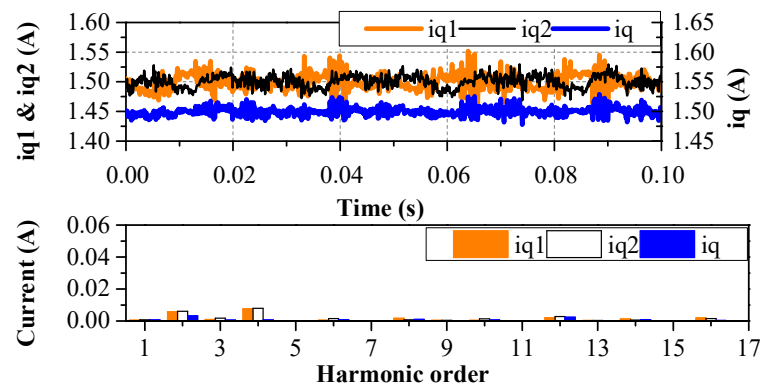

(d)

Fig. 8 Measured results of proposed method with 5 th and 7 th harmonics compensation (a) Phase A and X current and harmonic analysis, (b) $i_{d z}$ and $i_{q z}$ and harmonic analysis, (c) $d$-axis current and harmonic analysis, (d) $q$-axis current and harmonic analysis

The measured phase currents with proposed method are shown in Fig. 12(a) and are very sinusoidal. The $i_{d z}, i_{q z}$ and the corresponding harmonic analysis are shown in Fig. 12(b), it can be seen that the DC value, the 2nd current harmonics and 6th current harmonics are eliminated. Furthermore, from the $i_{d}$ and $i_{q}$ current profiles in Fig. 12(c) and corresponding harmonic analysis in Fig. 12(d), it can be seen the 2nd current harmonics in $d q$ frame are eliminated effectively as well. 

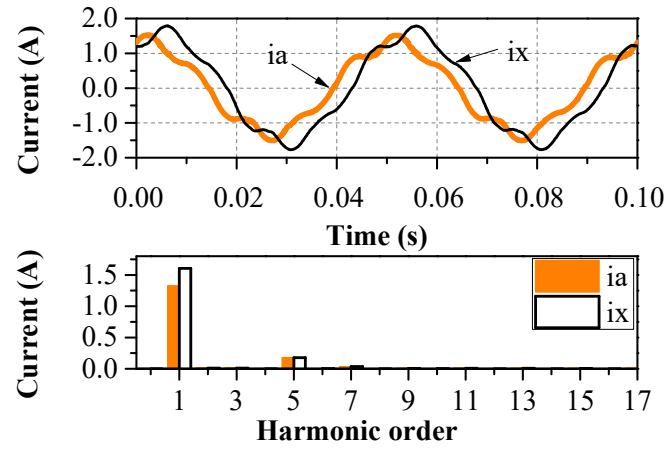

(a)
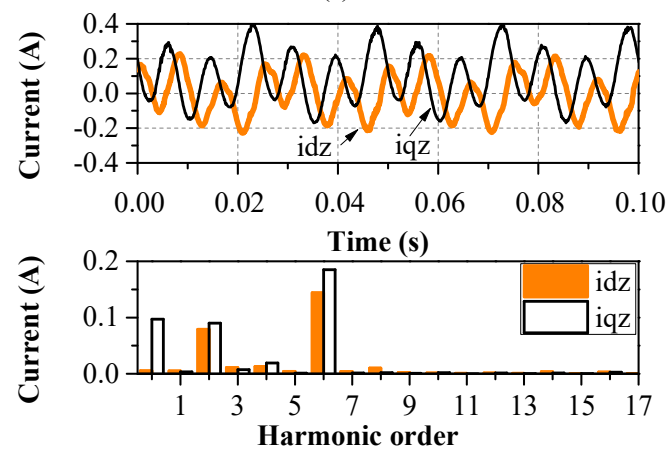

(b)

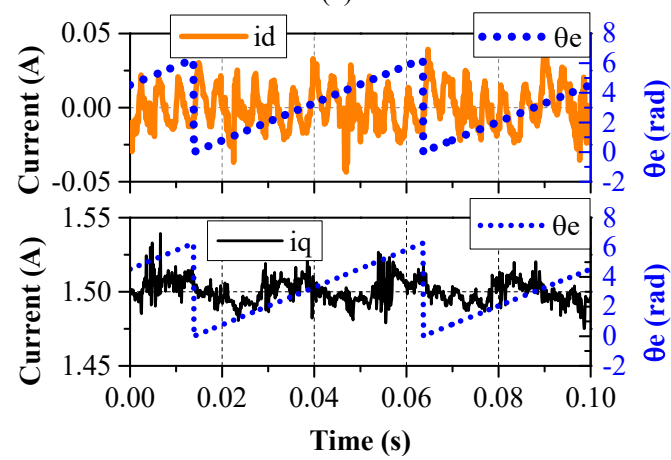

(c)

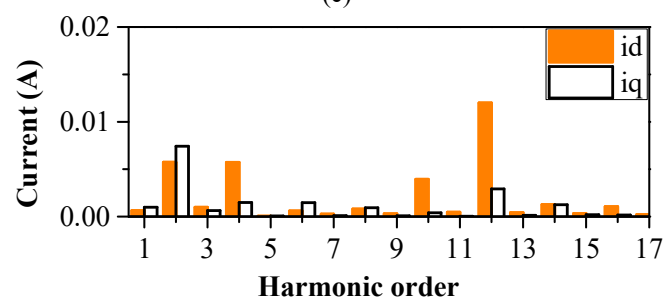

(d)

Fig. 9 Measured results without current control in $z_{1} z_{2}$ sub-plane and PI contro in $d q$ frame with an additional resistor $0.5 \Omega$ in series with phase A (a) Phase A and $\mathrm{X}$ currents and harmonic analysis, (b) $i_{d z}$ and $i_{q z}$ and harmonic analysis, (c) $i_{d}$ and $i_{q},(\mathrm{~d})$ Harmonic analysis of $i_{d}$ and $i_{q}$

In some applications, the bandwidth of PI control may be relatively low due to the low PWM switching frequency [47], especially in high power applications. In order to extend the current unbalance compensation strategy in some applications with low bandwidth and to demonstrate a clearer effect of the proposed 2nd order current harmonic compensation in $d q$ frame when the system is asymmetry, the experiment with reduced
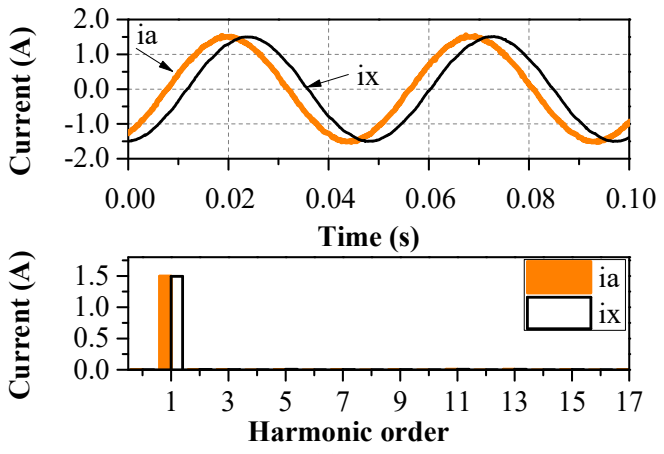

(a)
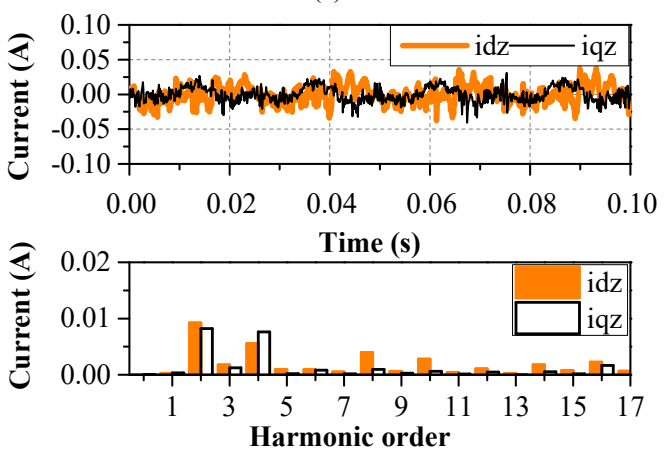

(b)

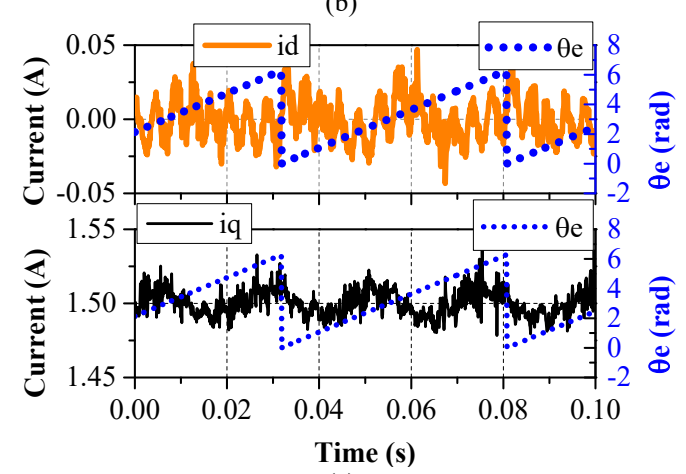

(c)

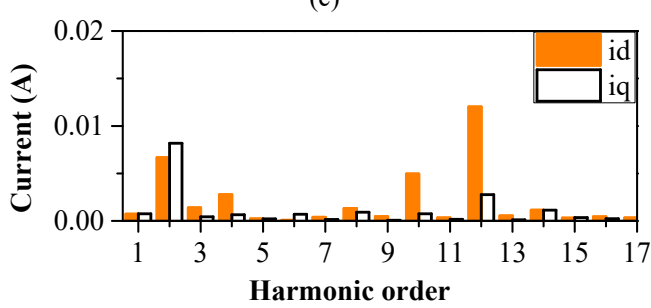

(d)

Fig. 10 Measured results with PI-R(6th) control in $d q z$ frame and PI control in $d q$ frame with an additional resistor $0.5 \Omega$ in series with phase A (a) Phase A and $\mathrm{X}$ currents and harmonic analysis, (b) $i_{d z}$ and $i_{q z}$ and harmonic analysis, (c) $i_{d}$ and $i_{q},(\mathrm{~d})$ Harmonic analysis of $i_{d}$ and $i_{q}$

gains and lower bandwidth is conducted and shown in Figs. 12 and 13. The PI-R gain values in $d q$ frame are deliberately reduced to $1 / 10$ of that shown in TABLE II, while the gain values in $d q z$ frame remain the same. 

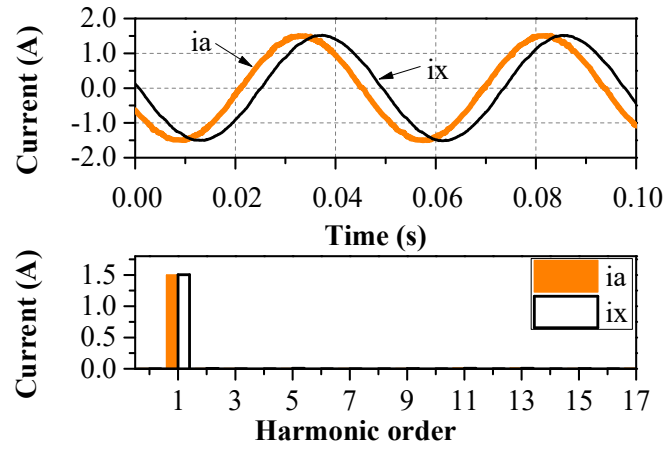

(a)

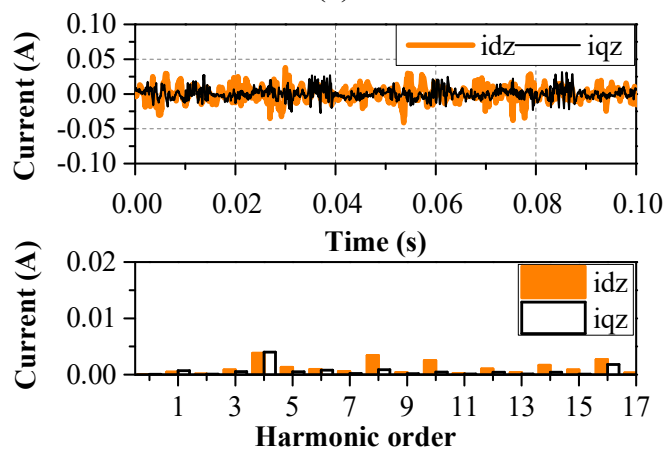

(b)

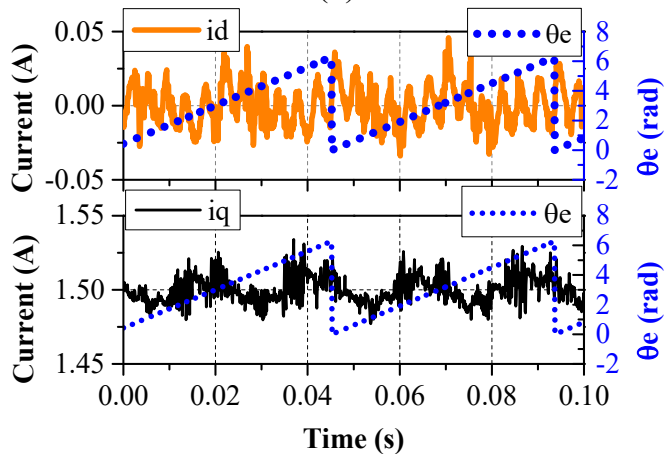

(c)

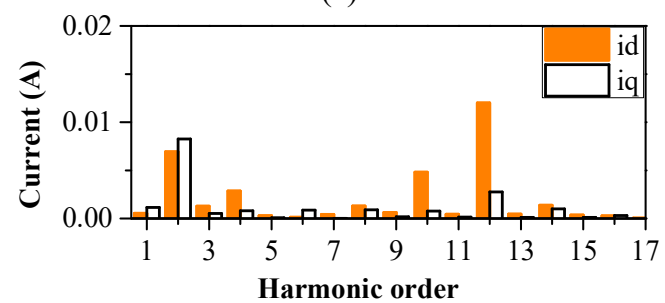

(d)

Fig. 11 Measured results with PI-R(6th+2nd) control in $z_{1} z_{2}$ frame and PI control in $d q$ frame with an additional resistor $0.5 \Omega$ in series with phase A (a) Phase $\mathrm{A}$ and $\mathrm{X}$ currents and harmonic analysis, (b) $i_{d z}$ and $i_{q z}$ and harmonic analysis, (c) $i_{d}$ and $i_{q}$, (d) Harmonic analysis of $i_{d}$ and $i_{q}$.

The experimental results with PI-R(6th and 2nd) control in $d q z$ frame and PI control in $d q$ frame, which is equivalent to the method presented in [17], are shown in Fig. 13. From Fig. 13(b), it can be seen that the 2 nd current harmonics in $d q z$ frame are eliminated, whereas the current unbalance in $\alpha \beta$ sub-plane is still significant, Fig. 13(a). Consequently, there are still obvious 2nd order current harmonics in $d q$ frame, Fig. 13(c) and (d). The
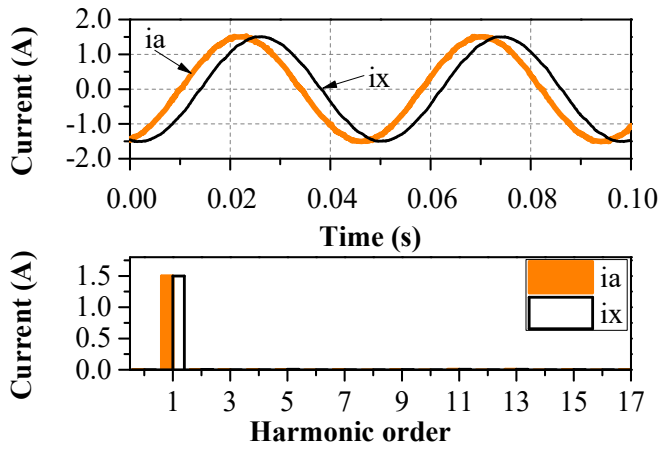

(a)
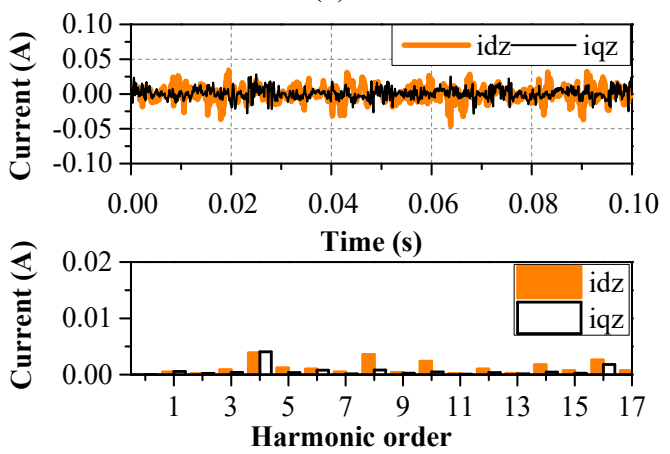

(b)

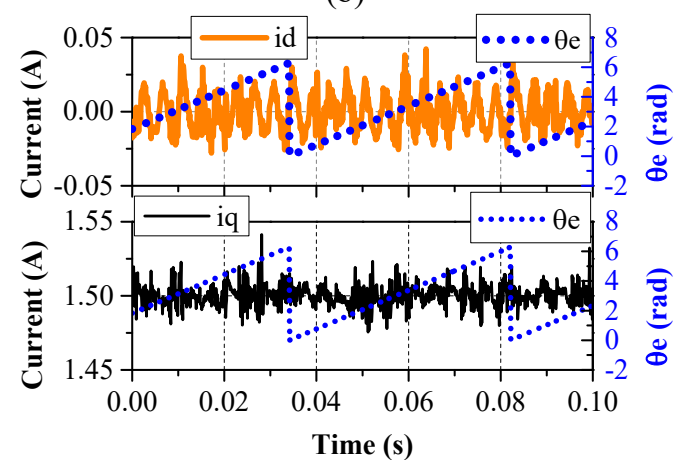

(c)

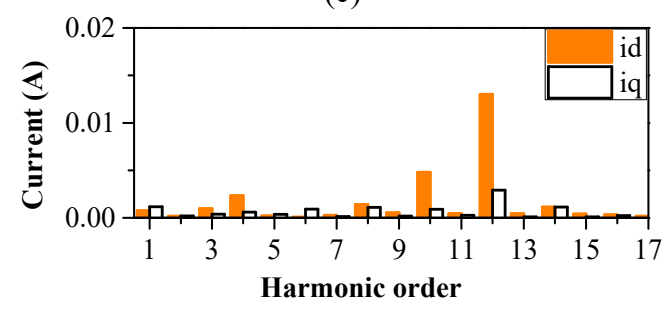

(d)

Fig. 12 Measured results of proposed current scheme with an additional resistor $0.5 \Omega$ in series with phase A (a) Phase A and X currents and harmonic analysis, (b) $i_{d z}$ and $i_{q z}$ and harmonic analysis, (c) $i_{d}$ and $i_{q}$, (d) Harmonic analysis of $i_{d}$ and $i_{q}$.

experimental results with the proposed method including the compensation of 2 nd order current harmonics in $d q$ frame, are shown in Fig. 14. It can be seen that the 2nd current harmonics in $d q z$ frame are eliminated, Fig. 14(b), while the 2nd order current harmonics in $d q$ frame are also eliminated as shown in Fig. 14 (c) and (d). Consequently, as can be seen from Fig. 14(a), the currents in $\alpha \beta$ sub-plane will be balanced. 

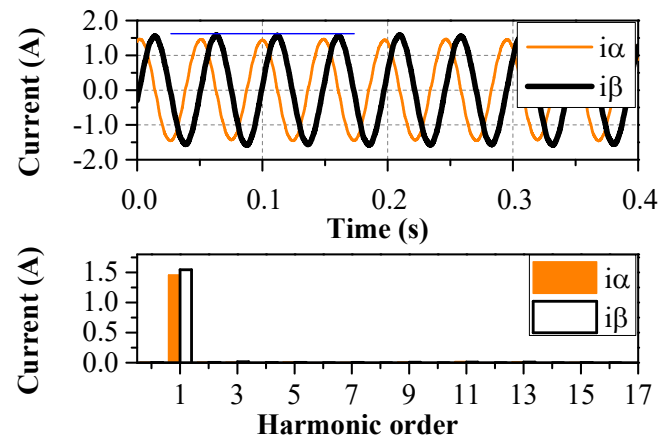

(a)
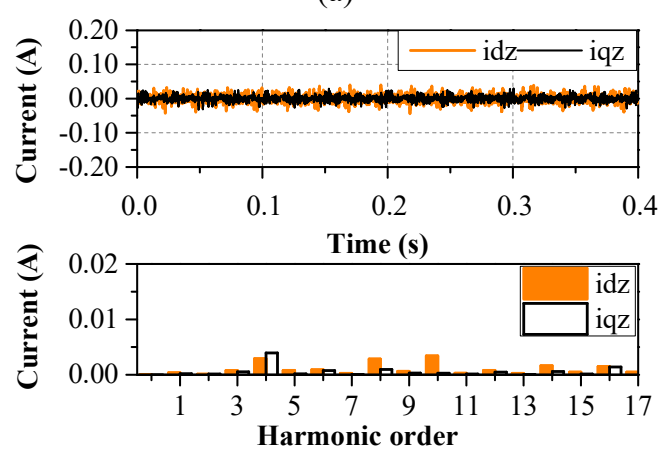

(b)

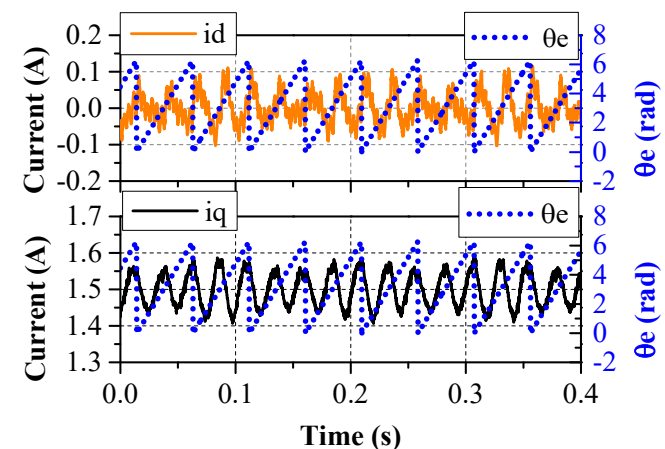

(c)

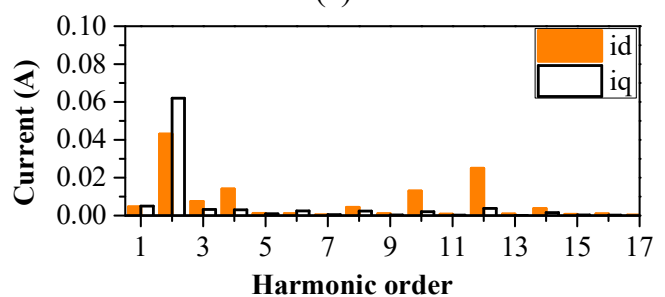

(d)

Fig. 13 Measured results with $\mathrm{PI}+\mathrm{R}(6 \mathrm{th}+2 \mathrm{nd})$ control in $d q z$ frame and $\mathrm{PI}$ control in $d q$ frame with an additional resistor $0.5 \Omega$ in series with phase A (a) Currents in $\alpha \beta$ sub-plane and harmonic analysis, (b) $i_{d z}$ and $i_{q z}$ and harmonic analysis, (c) $i_{d}$ and $i_{q}$, (d) Harmonic analysis of $i_{d}$ and $i_{q}$.

Overall, the proposed current control could be regarded as a competitive alternative for the elimination of current balance of dual 3-phase PMSM. Although the complexity of the current control is increased, this issue can be ignored in reality thanks to the fast development of micro controllers.

B. Dynamical Performance Comparison
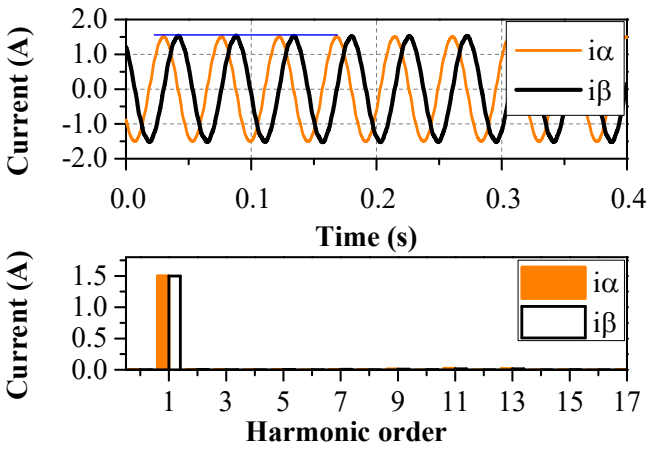

(a)
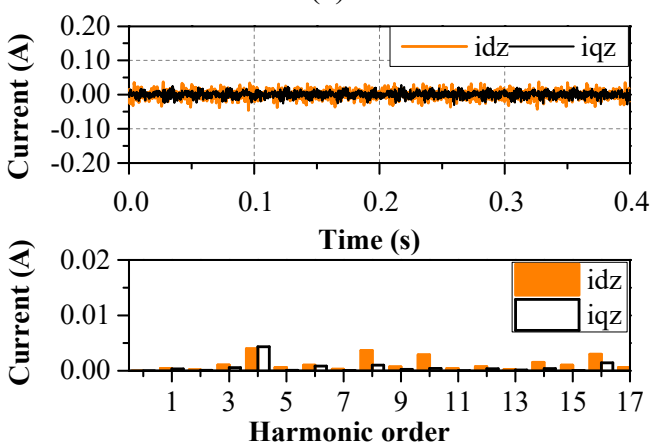

(b)

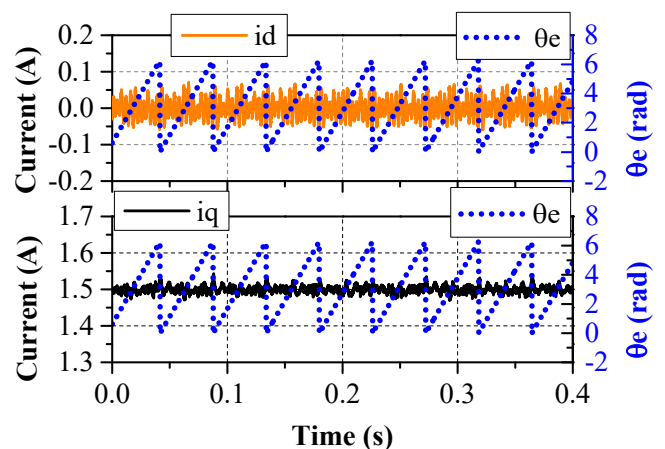

(c)

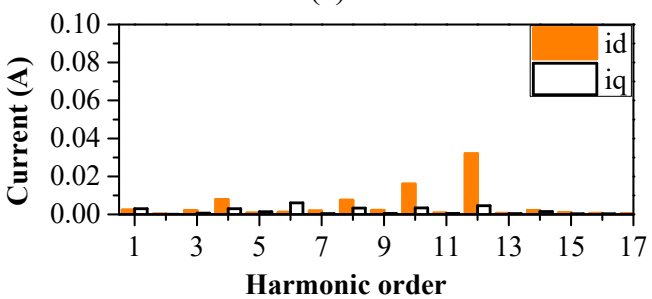

(d)

Fig. 14 Measured results of proposed current scheme with an additional resistor $0.5 \Omega$ in series with phase A (a) Currents in $\alpha \beta$ sub-plane and harmonic analysis, (b) $i_{d z}$ and $i_{q z}$ and harmonic analysis, (c) $i_{d}$ and $i_{q}$, (d) Harmonic analysis of $i_{d}$ and $i_{q}$.

Although the proposed method can achieve fully balanced currents, the dynamic performance of drive system will be slightly affected by the extra 2nd order current harmonics in $d q$ frame. The step current response with/without 2 nd order resonant control in $d q$ frame is shown in Fig. 15. The $i_{q}$ reference current is stepped from $1 \mathrm{~A}$ to $1.5 \mathrm{~A}$. 


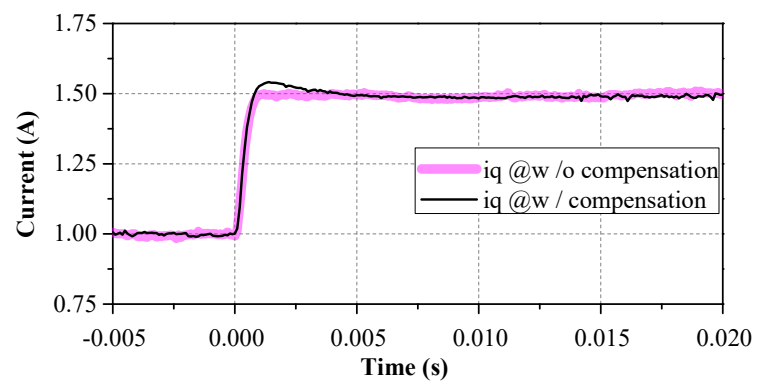

Fig. 15 Current step response with/without 2 nd order harmonics compensation in $d q$ frame in $\alpha \beta$ sub-plane

It can be seen that the settling time with compensation is longer than that without compensation because the use of resonant controllers in $d q$ frame will affect the decoupling control of the $d q$ current.

\section{V.CONCLUSION}

This paper has proposed an improved VSD current control scheme for dual 3-phase PMSMs having two sets of 3-phase windings spatially shifted by 30 electrical degrees. Compared with existing methods only accounting for current unbalance in $z_{1} z_{2}$ sub-plane, the proposed method has taken into account the current unbalances in both $z_{1} z_{2}$ and $\alpha \beta$ sub-planes and can eliminate them simultaneously at the steady state of operation. Consequently, the full compensation of current unbalance can be achieved, by which both the current unbalance between two sets and current unbalance between windings in each set are eliminated. Meanwhile, the 5th and 7th current harmonics caused by non-sinusoidal back EMF and inverter non-linearity can also be fully compensated. The effectiveness of proposed method is verified by a set of comparative experiments on a prototype dual 3-phase PM machine system. It shows that completely balanced currents without the 5 th and 7 th current harmonics at the steady state of operation can be achieved. Since this research only investigates the steady state performance of current control, it will be full of challenge to take into account the improvement of the dynamic torque performance in our future research.

\section{REFERENCES}

[1] T. M. Jahns, "Improved reliability in solid-state AC drives by means of multiple independent phase drive units," IEEE Trans. Ind. Appl., vol. IA-16, no. 3, pp. 321-331, 1980.

[2] K. Gopakumar, S. Sathiakumar, S. K. Biswas, and J. Vithayathil, "Modified current source inverter fed induction motor drive with reduced torque pulsations," IEE Proc. B Elect. Power Appl., vol. 131, no 4, pp. 159-164, 1984

[3] G. K. Singh, K. Nam, and S. K. Lim, "A simple indirect field-oriented control scheme for multiphase induction machine," IEEE Trans. Ind. Electron., vol. 52, no. 4, pp. 1177-1184, 2005.

[4] J. Karttunen, S. Kallio, P. Peltoniemi, P. Silventoinen, and O. Pyrhonen, "Dual three-phase permanent magnet synchronous machine supplied by two independent voltage source inverters," in Proc. Int. Symp. Power Electron., Electr. Drives, Autom. and Motion, 2012, pp. 741-747.

[5] E. Levi, R. Bojoi, F. Profumo, H. A. Toliyat, and S. Williamson, "Multiphase induction motor drives - A technology status review," IET Electr. Power Appl., vol. 1, no. 4, pp. 489-516, 2007.

[6] E. Levi, "Multiphase electric machines for variable-speed applications," IEEE Trans. Ind. Electron., vol. 55, no. 5, pp. 1893-1909, 2008.

[7] W. Cao, B. C. Mecrow, G. J. Atkinson, J. W. Bennett, and D. J. Atkinson, "Overview of electric motor technologies used for more electric aircraft
(MEA)," IEEE Trans. Ind. Electron., vol. 59, no. 9, pp. 3523-3531, 2012.

[8] H. Amimeur, D. Aouzellag, R. Abdessemed, and K. Ghedamsi, "Sliding mode control of a dual-stator induction generator for wind energy conversion systems," Int. J. Electr. Power Engery Syst., vol. 42, no. 1, pp. 60-70, 2012.

[9] K. Gopakumar, V. T. Ranganthan, and S. R. Bhat, "Split-phase induction motor operation from PWM voltage source inverter," IEEE Trans. Ind. Appl., vol. 29, no. 5, pp. 927-932, 1993.

[10] Y. Zhao and T. A. Lipo, "Space vector PWM control of dual three-phase induction machine using vector space decomposition," IEEE Trans. Ind. Appl., vol. 31, no. 5, pp. 1100-1109, 1995.

[11] K. K. Mohapatra, R. S. Kanchan, M. R. Baiju, P. N. Tekwani, and K. Gopakumar, "Independent field-oriented control of two split-phase induction motors from a single six-phase inverter," IEEE Trans. Ind. Electron., vol. 52, no. 5, pp. 1372-1382, 2005.

[12] D. Hadiouche, H. Razik, and A. Rezzoug, "On the modeling and design of dual-stator windings to minimize circulating harmonic currents for VSI fed AC machines," IEEE Trans. Ind. Appl., vol. 40, no. 2, pp. 506-515, 2004.

[13] D. Yazdani, S. Ali Khajehoddin, A. Bakhshai, and G. Joos, "Full utilization of the inverter in split-phase drives by means of a dual three-phase space vector classification algorithm," IEEE Trans. Ind. Electron., vol. 56, no. 1, pp. 120-129, 2009.

[14] A. R. Bakhshai, G. Joos, P. K. Jain, and J. Hua, "Incorporating the overmodulation range in space vector pattern generators using a classification algorithm," IEEE Trans. Power Electron., vol. 15, no. 1, pp. 83-91, 2000

[15] R. Bojoi, A. Tenconi, F. Profumo, G. Griva, and D. Martinello, "Complete analysis and comparative study of digital modulation techniques for dual three-phase AC motor drives," in Proc. IEEE 33rd Annu. Power Electron. Spec. Conf., 2002, pp. 851-857 vol.2.

[16] K. Marouani, L. Baghli, D. Hadiouche, A. Kheloui, and A. Rezzoug, "A new PWM strategy based on a 24-sector vector space decomposition for a six-phase VSI-Fed dual stator induction motor," IEEE Trans. Ind. Electron., vol. 55, no. 5, pp. 1910-1920, 2008.

[17] H. S. Che, E. Levi, M. Jones, W. P. Hew, and N. A. Rahim, "Current control methods for an asymmetrical six-phase induction motor drive," IEEE Trans. Power Electron., vol. 29, no. 1, pp. 407-417, 2014.

[18] R. Bojoi, F. Farina, M. Lazzari, F. Profumo, and A. Tenconi, "Analysis of the asymmetrical operation of dual three-phase induction machines," in Proc. IEEE Int. Electron. Mach. and Drives Conf., 2003, pp. 429-435 vol.1.

[19] R. Kianinezhad, B. Nahid, L. Baghli, F. Betin, and G. A. Capolino, "Aspects of current regulation in indirect field oriented control of dual three phase induction machines," in Proc. IEEE Int. Conf. Ind. Technol., 2006, pp. 933-938.

[20] R. Bojoi, M. Lazzari, F. Profumo, and A. Tenconi, "Digital field-oriented control for dual three-phase induction motor drives," IEEE Trans. Ind. Appl., vol. 39, no. 3, pp. 752-760, 2003.

[21] Y. He, Y. Wang, J. Wu, Y. Feng, and J. Liu, "A simple current sharing scheme for dual three-phase permanent-magnet synchronous motor drives," in Proc. 25th Annu. IEEE Appl. Power Elect. Conf. and Exposition, 2010, pp. 1093-1096.

[22] S. Kallio, M. Andriollo, A. Tortella, and J. Karttunen, "Decoupled d-q model of double-star interior-permanent-magnet synchronous machines," IEEE Trans. Ind. Electron., vol. 60, no. 6, pp. 2486-2494, 2013.

[23] J. Karttunen, S. Kallio, P. Peltoniemi, P. Silventoinen, and O. Pyrhonen, "Decoupled vector control scheme for dual three-phase permanent magnet synchronous machines," IEEE Trans. Ind. Electron., vol. PP, no. 99, pp. 1-1, 2013.

[24] R. Bojoi, F. Profumo, and A. Tenconi, "Digital synchronous frame current regulation for dual three-phase induction motor drives," in Proc. IEEE 34th Annu. Power Electron. Spec. Conf. , 2003, pp. 1475-1480 vol.3.

[25] R. Bojoi, E. Levi, F. Farina, A. Tenconi, and F. Profumo, "Dual three-phase induction motor drive with digital current control in the stationary reference frame," IEE Proc. - Elect. Pow. Appl., vol. 153, no. 1, pp. 129-139, 2006.

[26] H. S. Che, W. P. Hew, N. A. Rahim, E. Levi, M. Jones, and M. J. Duran, "Current control of a six-phase induction generator for wind energy 
plants," in Proc. 15th Int. Power Electron. and Motion Control Conf., 2012, pp. LS5b.2-1-LS5b.2-7.

[27] J. Liu, G. J. Yang, J. Y. Su, and J. B. Yang, "An improved vector control method for dual three phase PMSG," in Proc. 7th Int. Power Electron. and Motion Control Conf., 2012, pp. 1252-1256.

[28] J. W. Choi and S. K. Sul, "Inverter output voltage synthesis using novel dead time compensation," IEEE Trans. Power Electron., vol. 11, no. 2, pp. 221-227, 1996.

[29] H. S. Kim, K. H. Kim, and M.-J. Youn, "On-line dead-time compensation method based on time delay control," IEEE Trans. Control Syst. Technol., vol. 11, no. 2, pp. 279-285, 2003.

[30] D. N. Zmood, D. G. Holmes, and G. H. Bode, "Frequency-domain analysis of three-phase linear current regulators," IEEE Trans. Ind. Appl. vol. 37, no. 2, pp. 601-610, 2001.

[31] D. N. Zmood and D. G. Holmes, "Stationary frame current regulation of PWM inverters with zero steady-state error," IEEE Trans. Power Electron., vol. 18, no. 3, pp. 814-822, 2003.

[32] L. R. Limongi, R. Bojoi, G. Griva, and A. Tenconi, "Digital current-control schemes," IEEE Ind. Electron. Mag., vol. 3, no. 1, pp. 20-31, 2009.

[33] G. Escobar, A. M. Stankovic, and P. Mattavelli, "An adaptive controller in stationary reference frame for D-STATCOM in unbalanced operation," IEEE Trans. Ind. Electron., vol. 51, no. 2, pp. 401-409, 2004.

[34] I. Etxeberria-Otadui, A. L. de Heredia, H. Gaztanaga, S. Bacha, and M. R. Reyero, "A single synchronous frame hybrid (SSFH) multifrequency controller for power active filters," IEEE Trans. Ind. Electron., vol. 53, no. 5, pp. 1640-1648, 2006

[35] M. Liserre, R. Teodorescu, and F. Blaabjerg, "Multiple harmonics control for three-phase grid converter systems with the use of PI-RES current controller in a rotating frame," IEEE Trans. Power Electron., vol. 21, no. 3, pp. 836-841, 2006

[36] I. Etxeberria-Otadui, U. Viscarret, M. Caballero, A. Rufer, and S. Bacha, "New optimized PWM VSC control structures and strategies under unbalanced voltage transients," IEEE Trans. Ind. Electron., vol. 54, no. 5, pp. 2902-2914, 2007.

[37] J. B. Hu, Y. K. He, L. Xu, and B. W. Williams, "Improved control of DFIG systems during network unbalance using PI-R current regulators," IEEE Trans. Ind. Electron., vol. 56, no. 2, pp. 439-451, 2009

[38] L. L. Fan, R. Kavasseri, H. P. Yin, C. X. Zhu, and M. Q. Hu, "Control of DFIG for rotor current harmonics elimination," in Proc. IEEE Power \& Energy Soc., 2009, pp. 1-7.

[39] H. L. Xu, J. B. Hu, N. Heng, and Y. K. He, "Dynamic modeling and improved control of DFIG under unbalanced and distorted grid voltage conditions," in Proc. IEEE Int. Symp. Ind. Electron., 2012, pp. 1579-1584.

[40] C. Liu, F. Blaabjerg, W. Chen, and D. Xu, "Stator current harmonic control with resonant controller for doubly fed induction generator," IEEE Trans. Power Electron., vol. 27, no. 7, pp. 3207-3220, 2012.

[41] R. Bojoi, F. Farina, G. Griva, F. Profumo, and A. Tenconi, "Direct torque control for dual three-phase induction motor drives," IEEE Trans. Ind. Appl., vol. 41, no. 6, pp. 1627-1636, 2005.

[42] F. Barrero, M. R. Arahal, R. Gregor, S. Toral, and M. J. Duran, "One-step modulation predictive current control method for the asymmetrical dual three-phase induction machine," IEEE Trans. Ind. Electron., vol. 56, no. 6, pp. 1974-1983, 2009.

[43] F. Barrero, M. R. Arahal, R. Gregor, S. Toral, and M. J. Duran, "A proof of concept study of predictive current control for vsi-driven asymmetrical dual three-phase ac machines," IEEE Trans. Ind. Electron. vol. 56, no. 6, pp. 1937-1954, 2009

[44] R. Gregor, F. Barrero, S. L. Toral, M. J. Duran, M. R. Arahal, J. Prieto, and J. L. Mora, "Predictive-space vector PWM current control method for asymmetrical dual three-phase induction motor drives," IET Electr. Power Appl., vol. 4, no. 1, pp. 26-34, 2010.

[45] F. Barrero, J. Prieto, E. Levi, R. Gregor, S. Toral, M. J. Duran, and M. Jones, "An enhanced predictive current control method for asymmetrical six-phase motor drives," IEEE Trans. Ind. Electron., vol. 58, no. 8, pp. 3242-3252, 2011.

[46] M. J. Duran, J. Prieto, F. Barrero, and S. Toral, "Predictive current control of dual three-phase drives using restrained search techniques," IEEE Trans. Ind. Electron., vol. 58, no. 8, pp. 3253-3263, 2011.
[47] V. Blasko, V. Kaura, and W. Niewiadomski, "Sampling of discontinuous voltage and current signals in electrical drives: a system approach," IEEE Trans. Ind. Appl., vol. 34, no. 5, pp. 1123-1130, 1998.

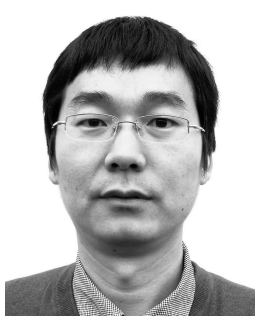

Yashan Hu received the B.Eng. and M.Sc. degrees in electrical engineering from Northwestern Polytechnical University, Xi'an, China, in 2002 and 2005 , respectively. He has been working toward the $\mathrm{Ph} . D$. degree at the University of Sheffield, Sheffield, U.K., since Jun 2012.

From 2005 to 2012, he was with Delta Green Tech (China) Co., Ltd., Shanghai, China, Shanghai Yungtay Elevator Co. Ltd as a Research Engineer, and Shanghai Welling Motor R\&D Centre as Project Manager. His research interests are control of electric drives.

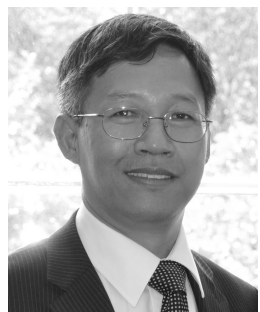

Z. Q. Zhu (M'90-SM'00-F'09) received the B.Eng. and M.Sc. degrees from Zhejiang University, Hangzhou, China, in 1982 and 1984, respectively, and the Ph.D. degree from the University of Sheffield, Sheffield, U.K., in 1991, all in electrical engineering.

From 1984 to 1988, he lectured in the Department of Electrical Engineering, Zhejiang University. Since 1988, he has been with the University of Sheffield, where since 2000, he has been a Professor of electrical machines and control systems in the Department of Electronic and Electrical Engineering, and is currently the Head of the Electrical Machines and Drives Research Group. His current major research interests include the design and control of permanent-magnet brushless machines and drives for applications ranging from automotive to renewable energy.

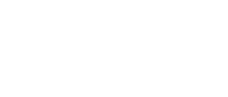

Kan Liu received the B.Eng. and Ph.D. degrees in automation from the Hunan University, China, in 2005 and 2011, respectively, and was awarded a Ph.D degree in electronic and electrical engineering from the University of Sheffield, Sheffield, U.K., in 2013.

$\mathrm{He}$ is currently working as a research associate in the Department of Electronics and Electrical Engineering at the University of Sheffield. His research interest focuses on parameters estimation and sensorless control of permanent magnet synchronous machine drives. 